\title{
PETROLOGIA E TERMOCRONOLOGIA DE GNAISSES MIGMATÍTICOS DA FAIXA DE DOBRAMENTOS ARAÇUAÍ (ESPIRITO SANTO, BRASIL)
}

\author{
JOSÉ M. U. MUNHÁ ${ }^{1}$, UMBERTO G. CORDANI ${ }^{2}$, COLOMBO C. G. TASSINARI ${ }^{2}$ \& \\ TERESA PALÁCIOS ${ }^{1}$
}

\begin{abstract}
PETROLOGY AND THERMOCHRONOLOGY OF MIGMATITIC GNEISSES OF THE ARAÇUAÍ FOLD BELT (ESPÍRITO SANTO, BRAZIL) Migmatitic gnaisses of the Araçuaí Fold Belt (Espirito Santo, Brazil) experienced granulite facies metamorphism $\left(820 \pm 20^{\circ} \mathrm{C} ; 6.5 \pm 0.5 \mathrm{kbar}\right)$ during the late stages of the Brasiliano Orogeny. These conditions remained for a long period ( $530 \mathrm{Ma} ? \sim 480 \mathrm{Ma}$ ), close to peak metamorphic conditions and promoted muscovite + biotite partial melting, followed by retrograde reactions that produced late cordierite + biotite and garnet reabsorption. Fe- $\mathrm{Mg}$ garnet-biotite exchanges, as well as diffusion modeling, indicate cooling rates between 20 and $300^{\circ} \mathrm{C} / \mathrm{Ma}$ between 750 and $550^{\circ} \mathrm{C}$. Geochronology on garnet, plagioclase, biotite and Kfeldspar yielded consistent results and cooling ages between 475 and $420 \mathrm{Ma}$. The geochronological results are consistent with diffusion models, and indicate a short period of rapid cooling followed by a longer period of slow cooling at rates close to $2^{\circ} \mathrm{C} /$ Ma. The initial rapid cooling is interpreted as due to the thrusting of the migmatitic gnaisses onto cooler basement rocks.
\end{abstract}

Keywords: Petrology, Thermochronology, Gnaisses, Araçuaí Belt, Brazil

Resumo Os gnaisses migmatíticos da Faixa de Dobramentos Araçuaí foram submetidos a metamorfismo em condições da fácies granulito $\left(820 \pm 30^{\circ} \mathrm{C}, 6.5 \pm 0.5 \mathrm{kbar}\right)$ durante os estágios finais da orogenia Brasiliana. O metamorfismo de alto grau ocorreu durante longo tempo ( $530 \mathrm{Ma}$ ? $\sim 80 \mathrm{Ma})$ e foi acompanhado de fusão parcial de muscovita e biotita, a que se seguiram reações retrógradas produzindo cordierita + biotita e intensa reabsorção de granada. Modelamento da troca difusiva Fe-Mg (granada-biotita) sugere taxas de resfriamento entre 20 e $300^{\circ} \mathrm{C} / \mathrm{Ma}$, entre $750^{\circ} \mathrm{C}$ e $550^{\circ} \mathrm{C}$. Geocronologia absoluta de granada, plagioclásio, biotita e feldspato potássico produziu idades de resfriamento a $475 \pm 6 \mathrm{Ma}, 473 \pm 8 \mathrm{Ma}, 470 \pm 2 \mathrm{Ma}$ e $440-420 \mathrm{Ma}$, respectivamente. Os resultados são congruentes com os modelos de difusão, sendo consistentes com um curto período de resfriamento rápido a partir de $\sim 480 \mathrm{Ma}(<$ $\left.10 \mathrm{Ma} \mathrm{a} \geq 60^{\circ} \mathrm{C} / \mathrm{Ma}\right)$, o qual sucedeu declínio acentuado das taxas de resfriamento $\left(\sim 2^{\circ} \mathrm{C} / \mathrm{Ma}\right)$. A história térmica do resfriamento requer exumação inicial rápida, justapondo os gnaisses migmatíticos às unidades cratonizadas mais frias. À medida que cessaram os esforços tectônicos tangenciais, a dissipação da instabilidade termo-gravitacional foi condicionada por transferência de calor conductiva e compensação isostática, em conformidade com o declínio das taxas de resfriamento.

Palavras-chave: Petrologia, Termocronologia, Gnaisses, Faixa Araçuaí, Brasil

INTRODUÇÃO A área estudada situa-se na região leste do Brasil, no Estado do Espírito Santo, entre $18^{\circ} 30^{\prime}$ e $20^{\circ} \mathrm{Sul} 40^{\circ} \mathrm{e} 41^{\circ}$ Oeste. Sob o ponto de vista geológico, a Faixa de Dobramentos Araçuaí, bem como a Faixa Ribeira que situa-se em sua continuidade para o sul, e em conjunto com o Cinturão do "West Congo", limitam os Crátons do São Francisco e do Congo. O sistema orogênico Neoproterozóico - Eopaleozóico, Araçuaí - West Congo constituiu o segmento norte da Cadeia Orogênica Brasiliana/PanAfricana, composta pelos Cinturões Móveis Ribeira, Dom Feliciano e Gariep, Damara e Kaoko, que ocorrem no sul-sudeste do Brasil e no oeste da África, respectivamente.

As rochas que afloram na área de estudo pertencem ao Grupo Paraíba do Sul, o qual inclui dois domínios litológicos (Pedrosa Soares \& Wiedemann-Leonardos 2000). O mais antigo é constituído por granulitos \pm charnoquíticos e granitóides deformados (ortognaisses), que ocorrem sob a forma de núcleos preservados em meio a uma sequência mais jóvem metamórfica paraderivada, onde predominam gnaisses pelíticos/psamíticos migmatizados. $\mathrm{O}$ objetivo deste trabalho é caracterizar as condições físicas deste evento metamórfico, em particular, o regime P-T e a respectiva evolução termocronológica, contribuindo para o esclarecimento da evolução termotectônica regional.

\section{METAMORFISMO E MIGMATIZAÇÃO Os gnaisses}

migmatíticos compreendem leucossomas quartzo-feldspáticos $(+$ biotita \pm granada \pm cordierita) e metapelitos, interpretados como o material fundido e resíduo refratário, respectivamente. O leucossoma constitui frequentemente $>10 \%$ das rochas expostas; contudo, oscilações no grau de fusão parcial e na eficiência dos mecanismos de segregação magmática produziram relações texturais complexas, desde intercalações intimas entre leucossoma e metapelito com preservação de foliação/bandeado metamórfico, onde a fusão parcial e a segregação magmática foram limitadas, até situações onde o leucossoma predomina, incluindo corpos dispersos de restitos. A coalescência final destes leucossomas poderá ter originado os granitóides regionais descritos por Pedrosa Soares et al. (2001).

A recristalização metamórfica e migmatização relacionam-se com deformação dúctil, polifásica, em regime transpressivo (Pedrosa Soares \& Wiedemann-Leonardos 2000). A anisotropia $\left(\mathrm{S}_{\mathrm{M}}\right)$ metamórfica principal transpôs foliação(ões) prévia, refletindo, em todas as escalas, o desenvolvimento regional de sistemas de cisalhamento dominantemente dextral que produziram cavalgamentos e forte imbricação tectônica, o que resultou numa estrutura em flor com vergências para $\mathrm{E}$ e W, no sentido dos crátons. $\mathrm{O}$ desenvolvimento frequente de porfiroblastos com $\mathrm{S}_{\mathrm{i}} \equiv \mathrm{S}_{\mathrm{M}}$, e a deformação incipiente nos leucossomas indicam que a maximização do regime térmico metamórfico teria ocorrido durante e/ou após o 
período de deformação principal.

O grau metamórfico atingiu a fácies granulíto, sendo típica dos metapelitos a associação granada-biotita-cordierita-feldspato potássico-plagioclásio-quartzo \pm (sillimanita, ortopiroxênio, espinélio, ilmenita). As paragêneses de alto grau estão geralmente bem preservadas, e o desenvolvimento de muscovita retrógrada, exceto a sericitização tardia dos feldspatos, raramente ocorre.

Nos gnaisses migmatíticos o bandeado composicional coincide com a foliação metamórfica é materializada pela biotita e raramente sillimanita. Esta foliação anastomosa-se entre os níveis de quartzo, feldspato potássico micropertítico e plagioclásio antipertítico, definindo a matriz, de onde sobressaem porfiroblastos de granada e cordierita. Estes porfiroblastos ocorrem em quase todas as amostras estudadas, onde podem ocorrer em cristais centimétricos. A cordierita tende a ser quimicamente homogênea na escala da lâmina delgada, e não apresenta evidências texturais que indiquem reações de reabsorção significativas. Pelo contrário, as granadas têm forma amebóide, contêm inclusões de quartzobiotita-sillimanita-plagioclásio(raro)-ilmenita, e mostram frequentemente intensa reabsorção em zonas de reação onde se desenvolvem cordierita + feldspato potássico + biotita. Almandina e piropo são zonados, com incremento de $\mathrm{Fe} /(\mathrm{Fe}+\mathrm{Mg})$ do núcleo dos cristais para a borda (UT-41: $0.73 \rightarrow 0.81$ ). O zoneamento pode ser concêntrico em torno do núcleo, mas também ocorre em granada adjacente à biotita e/ou cordierita. $\mathrm{O}$ zoneamento da razão $\mathrm{Fe} /$ (Fe+Mg) é retrógrado e interpretado como reflexo da difusão em volume, induzida por gradientes químicos impostos por reações contínuas do tipo:

cordierita + biotita $=$ granada + Kfeldspato + liquido $(1)$

cordierita + Kfeldspato $=$ granada + sillimanita + liquido $(2)$

sillimanita + biotita $=$ granada + Kfeldspato $+\mathrm{H}_{2} \mathrm{O}(3)$ cordierita $=$ granada + sillimanita $+\mathrm{H}_{2} \mathrm{O}(4)^{2}$

Análises detalhadas mostram que existe correlação entre o valor $\mathrm{Fe} /(\mathrm{Fe}+\mathrm{Mg})$ da biotita inclusa na granada e as dimensões, respectivas (UT-4: $\mathrm{Fe} /(\mathrm{Fe}+\mathrm{Mg})_{\text {biotita }}=0.33$, diâmetro $=20 \mu \mathrm{m} ; \mathrm{Fe} /$ $(\mathrm{Fe}+\mathrm{Mg})_{\text {biotita }}=0.41$, diâmetro $\left.=200 \mu \mathrm{m}\right)$. Isto é consistente com a interpretação de que o zoneamento $\mathrm{Fe}-\mathrm{Mg}$ da granada, bem como a distribuição de $\mathrm{Fe} /(\mathrm{Fe}+\mathrm{Mg})$ na biotita, é consequência do balanço de massa durante a dissipação difusiva dos gradientes causados pela partição $\mathrm{Fe}-\mathrm{Mg}$ entre os volumes das inclusões de biotita e da granada hospedeira, o que será utilizado posteriormente para inferir taxas de resfriamento. Os valores de $\mathrm{Fe} /(\mathrm{Fe}+\mathrm{Mg})$ na biotita também são função da respectiva localização na amostra; os valores $\mathrm{Fe} /(\mathrm{Fe}+\mathrm{Mg})$ mais baixos são observados na biotita inclusa na granada, enquanto os mais elevados correspondem, geralmente à biotita da matriz (UT-27: $\mathrm{Fe} /(\mathrm{Fe}+\mathrm{Mg})_{\text {biotita na granada }}<$ $\left.0.45 ; \mathrm{Fe} /(\mathrm{Fe}+\mathrm{Mg})_{\text {biotita na matriz }}=0.52\right)$. A heterogeneidade composicional da biotita suporta a interpretação do zoneamento concêntrico descrito na granada, e ambos podem ser explicados se considerarmos que o progresso das reações (1) e (3) no sentido retrogrado (i.e., da direita para a esquerda) incrementa os valores $\mathrm{Fe} /(\mathrm{Fe}+\mathrm{Mg})$, quer na granada quer na biotita em consequência de: $\mathrm{Fe} / \mathrm{Mg}$ (granada) $\gg$ Fe/Mg (biotita) $>\mathrm{Fe} / \mathrm{Mg}$ (cordierita). Assim, á medida que a granada é consumida, a borda torna-se progressivamente mais rica em Fe que o núcleo, produzindo o zoneamento composicional observado, e o $\mathrm{Fe} /(\mathrm{Fe}+\mathrm{Mg})$ da biotita da matriz, equilibrada com as reações (1) e/ou (3), será mais elevado do que na biotita inclusa na granada, excedendo mesmo os valores Fe/ $(\mathrm{Fe}+\mathrm{Mg})$ da biotita produzida durante o pico metamórfico. Este padrão composicional é característico de biotita em rochas metamórficas de alto grau, tendo consequências importantes nos cálculos geotermométricos (Robinson 1991).

Observação notável nas amostras estudadas é a raridade da sillimanita matricial. Embora constituinte mineral freqüente, a sillimanita está, quase sempre limitada à forma de inclusões muitas vezes orientadas no interior dos porfiroblastos de granada, cordierita e feldspato potássico. Espinélio verde $\left(\mathrm{X}_{\mathrm{Mg}}=0.23\right.$, Al\# $=0.96$ ), embora raro, acompanha a sillimanita como inclusões ou intercrescimentos no interior de cordierita; associam-se-lhe, quartzo, feldspato potássico e biotita, bem como magnetita + ilmenita (tardias). Estas características modais têm implicações significativas na definição do percurso P-T metamórfico, a seguir discutido.

Geotermobarometria: máximo térmico e fusão parcial Geobarômetros aplicáveis às rochas estudadas incluem: granada + plagioclásio + sillimanita + quartzo (GASP), granada + ortopiroxênio + plagioclásio + quartzo (GOSP) e granada + cordierita + sillimanita + quartzo. A figura 1 mostra a gama de condições P-T inferidas destes equilíbrios, utilizando a base de dados termodinâmicos de Berman (1988) e as calibrações de Berman \& Aranovich (1996). Acima das temperaturas necessárias à fusão incongruente da biotita, e ao desenvolvimento de leucossomas com granada + cordierita, as relações de equilíbrio granada + plagioclásio + sillimanita indicam pressões mínimas da ordem de 6 - 7 kbar, enquanto que a intersecção dos equilíbrios GASP, GOSP e granada + cordierita + sillimanita produzem estimativas geobarométricas consistentes de $6.5 \pm 0.5 \mathrm{kbar}$, a $800-820^{\circ} \mathrm{C}$.

Geotermometria clássica, baseada na troca $\mathrm{Fe}-\mathrm{Mg}$ entre granada e biotita (Ferry \& Spear 1978) não pode ser usada para estimar as temperaturas de pico metamórfico porque, conforme os argumentos anteriormente apresentados, a assunção de equilíbrio generalizado entre uma biotita qualquer e a composição nuclear dos cristais de granada, frequentemente interpretados como representativo do pico metamórfico não é demonstrável. Nas rochas estudadas, as temperaturas calculadas com base na biotita inclusa na granada e usando os núcleos de granadas e a calibração de Berman \& Aranovich (1996), variam entre $650^{\circ} \mathrm{Ce} 780^{\circ} \mathrm{C}(550$ $750^{\circ} \mathrm{C}$, se utilizada a calibração de Berman 1990), o que reflete a

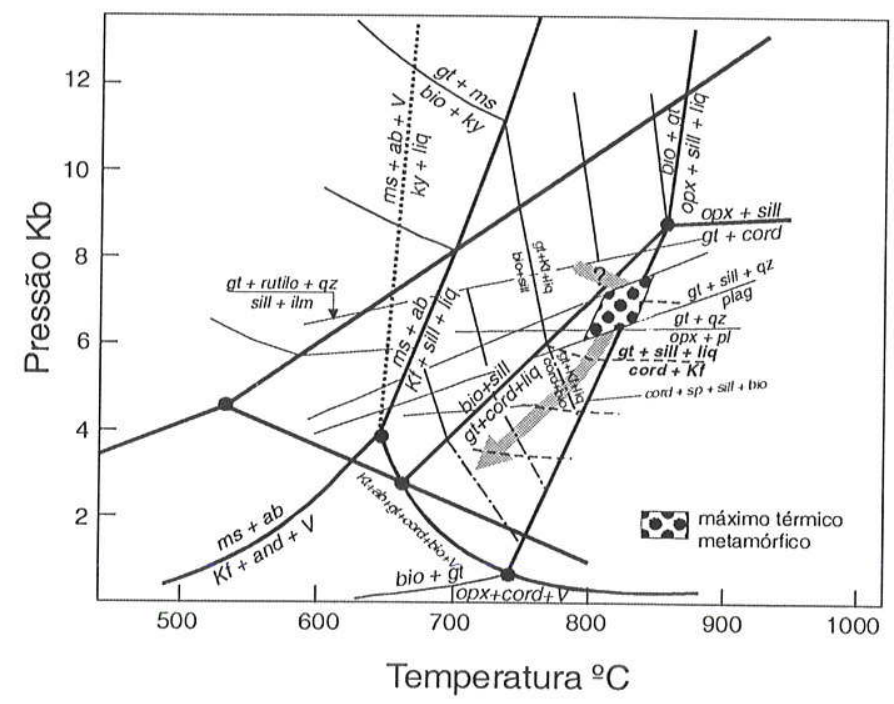

Figura 1-Diagrama P-T para os gnaisses migmatíticos da Faixa de Dobramentos Araçuai. Rede petrogenética adaptada de Spear et al. (1999) 
atuação do re-equilíbrio difusivo retrogrado, enquanto a biotita da matriz, como esperado produz estimativas por excesso $\left(>900^{\circ} \mathrm{C}\right)$. $\mathrm{O}$ valor de $\mathrm{T} \sim 780^{\circ} \mathrm{C}$ deve aproximar-se, por deficiência, de $\mathrm{T}_{\max }$, sendo consistente com a estimativa de $803 \pm 30^{\circ} \mathrm{C}$, obtida com base no método TWQ (Berman 1991, Berman \& Aranovich 1996), com a paragênese granada-plagioclásio-feldspatoK-ortopiroxêniobiotita-quartzo-(cordierita ?), representativa do mais alto-grau metamórfico observado na região.

Estimativas de $\mathrm{T}_{\text {max }}$ podem também, com vantagem, ser obtidas com base nos dados experimentais sobre reações de fusão parcial no sistema pelítico/psamítico (Fig. 1; Spear et al. 1999). A abundância de migmatitos demonstra a ocorrência de evento(s) de fusão parcial nas rochas estudadas e o volume considerável de leucossoma, observável em muitos afloramentos, sugere que a fusão "desidratante" (Thompson 1982) deve ter sido dominante. A ausência de muscovita primária e a presença da associação sillimanita-feldspato potássico-quartzo requerem temperatura superior as da estabilidade da muscovita + quartzo

muscovita + quartzo $=$ sillimanita + Kfeldspato + liquido (5) $\left(\mathrm{T}>700^{\circ} \mathrm{C}\right.$ ), enquanto que o desenvolvimento progrado de grana$\mathrm{da}+$ cordierita + feldspato potássico ocorreu provávelmente a T > $750-800^{\circ} \mathrm{C}$, por reações de fusão parcial, tais como:

biotita + sillimanita + plagioclásio + quartzo = granada + Kfeldspato + liquido (6)

biotita + sillimanita + quartzo $=$ granada + cordierita + Kfeldspato + liquido (7)

Finalmente, a raridade/ausência da associação ortopiroxênio + cordierita, cuja ocorrência não foi constatada, mas inferida de pseudomorfoses, sugere que a reação:

biotita + granada + quartzo $=$ ortopiroxênio + cordierita + Kfeldspato + liquido (8)

não deve ter sido significativamente ultrapassada, o que implica em $\mathrm{T} \leq 850^{\circ} \mathrm{C}$. Estas reações, em conjunto com os dados geotermobarométricos, delimitam as condições T-P de pico metamórfico a $820 \pm 30^{\circ} \mathrm{C}, 6.5 \pm 0.5 \mathrm{kbar}$ (Fig. 1).

Percurso P-T metamórfico A memória do percurso P-T durante a evolução progressiva foi apagada pelas reações de fusão parcial a alta-T e re-equilíbrios subseqüentes. Contudo, a associação biotita + sillimanita preservada no interior da granada sugere um percurso P-T direto, eventualmente envolvendo descompressão e aquecimento até às condições de pico metamórfico, como é característico dos orógenos que envolvem sobre-espessamento da crosta seguido de colapso orogênico. A ausência de rutilo, conjugada com a presença freqüente de ilmenita, limita a descompressão a $<1$ kbar (Fig. 1).

As características do percurso metamórfico retrogressivo podem ser analisadas sob a perspectiva do esquema petrogenético de Spear et al. (1999; Fig. 1). Reabsorção de granada, cristalização tardia de cordierita + feldspato potássico \pm biotita, intercrescimentos de cordierita + espinélio + sillimanita e os porfiroblastos de granada \pm cordierita em leucossomas, indicam que o processo retrogressivo foi condicionado predominantemente pelas reações (1) e (2), com envolvimento de intensa descompressão inicial (dP/dT > reação 7). A ausência de sillimanita retrogressiva (reações 6 e 7) e muscovita secundária sugerem que o resfriamento final se processou a $\mathrm{P} \leq 3 \mathrm{kbar}$.

TAXASDE RESFRIAMENTO: TERMOCRONOLOGIA A trajetória P-T seguida pelos gnaisses migmatíticos estudados (Fig. 1) reflete a interação entre o relaxamento térmico do segmento crustal e a descompressão e resfriamento causados pelo subsequente transporte das rochas para a superfície. Termocronologia refere-se a história térmica do metamorfismo. Neste contexto, a determinação das taxas de resfriamento do terreno metamórfico em estudo é importante, na medida em que permite caracterizar os mecanismos responsáveis pela exumação. Em geral, quanto mais rápida a exumação, mais elevada a taxa de resfriamento.

Datações radiométricas para geocronologia absoluta, de minerais com diferentes temperaturas de fechamento (Dodson 1973), têm sido utilizadas extensivamente para inferir taxas de resfriamento em terrenos metamórficos (Heaman \& Parrish 1991; McDougall \& Harrison 1999). Contudo, as taxas de resfriamento podem também ser determinadas pela análise dos mecanismos de difusão em minerais metamórficos (Lasaga et al. 1977), referidas como "taxas de resfriamento petrológicas" (Spear \& Parrish 1996). Neste estudo, a análise comparativa dos dois métodos é importante, não só para aferir a consistência interna das taxas de resfriamento determinadas em ambos, mas também porque a informação obtida se complementa.

Taxas de resfriamento petrológicas A teoria e métodos que utilizam os mecanismos de difusão para determinar taxas de resfriamento são descritos extensivamente na literatura especializada (Dodson 1973, Lasaga et al. 1977, Ehlers et al. 1994, Spear \& Parrish 1996) não sendo, portanto, aqui discutidos.

O método adotado neste estudo é idêntico ao proposto por Spear \& Parrish, (1996), que utiliza o modelamento da troca difusiva de Fe e Mg entre as inclusões de biotita e a granada hospedeira para inferir taxas de resfriamento das respectivas rochas metamórficas. Assume-se que a difusão induzida pelas variações composicionais na interface granada-biotita é dada pela alteração do coeficiente de distribução $K_{D}(\mathrm{Mg} / \mathrm{Fe})^{\text {gr-bio }}$ em resposta às variações da temperatura. Em cada caso, durante o resfriamento a granada enriquece-se em $\mathrm{Fe} /(\mathrm{Fe}+\mathrm{Mg})$ enquanto que as inclusões de biotita se empobrecem, até que, a uma temperatura suficientemente baixa (Tc - temperatura de fechamento) o processo cessa. Considerando que o processo difusivo é limitado pela taxa de difusão na granada, dado por:

$$
D_{F e-M g}^{b i o} \gg>D_{F e-M g}^{g r}
$$

e que o balanço de massa determina, em cada momento, a igualdade dos fluxos difusivos entre granada e biotita, as variações de Fe/ ( $\mathrm{Fe}+\mathrm{Mg}$ ) serão função da dimensão das inclusões com alterações composicionais mais intensas nas inclusões menores de biotita. Assim, o valor de $\mathrm{Fe} /(\mathrm{Fe}+\mathrm{Mg})$ em cada inclusão de biotita pode ser transformado na respectiva Tc, por confronto com a composição do núcleo da granada hospedeira, refletindo o fluxo difusivo total granada $\rightarrow$ biotita, que é função da evolução termocronológica.

A figura 2 representa diagramáticamente as relações $\mathrm{Tc}-\log$ (diâmetro biotita) nas amostras estudadas. Apesar da dispersão considerável, é aparente uma correlação entre a dimensão da biotita e as temperaturas de fechamento. A comparação entre as estimativas de Tc nas inclusões de bitotita e os resultados da simulação computacional baseados na difusão $\mathrm{Fe}-\mathrm{Mg}$ na granada e biotita, também consta da figura 2 .

No algoritmo computacional, as condições iniciais representam biotita e granada homogêneas à temperatura determinada para o pico metamórfico $\left(\mathrm{T}_{0} \sim 800^{\circ} \mathrm{C}\right)$. Durante o resfriamento as composições na interface granada-biotita variam de acordo com

$$
K_{D(M g / F e)}^{g r-b i o}=f[T(t)]
$$




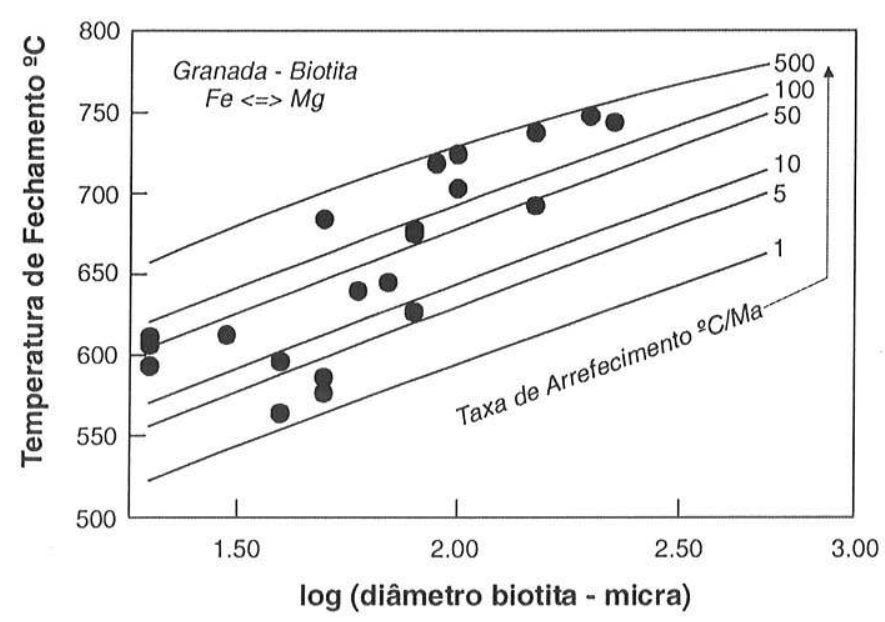

Figura 2 - Representação diagramática das relações entre a temperatura de fechamento, biotita (inclusão)-granada (Berman 1990), e a dimensão da biotita (log diâmetro - biotita). As linhas correspondem ao lugar geométrico dos pontos com igual taxa de resfriamento. Cálculos conforme com os modelos de difusão discutidos no texto.

em função da história térmica $\left(\mathrm{T}^{\circ} \mathrm{C}=\mathrm{g}(\mathrm{t} \mathrm{Ma})\right)$ simulada, e o modelo das diferenças finitas aproxima a solução da equação diferencial parcial

$$
\frac{\partial C}{\partial T}=D_{l \cdot e-M g}^{g r} \times \frac{\partial^{2} C}{\partial x^{2}}
$$

da difusão (granada - geometria esférica; biotita - cilíndrica), utilizando o coeficientes de inter-difusão Fe-Mg

$$
D_{F e-M g}^{g r}=D_{0} \times \exp (-Q / R T)
$$

calculados (Lasaga 1979) a partir dos dados experimentais de Chakraborty \& Ganguly (1992).

A estimativa da taxa de resfriamento é obtida por comparação estatística com os modelos de difusão, por regressão linear dos dados geotermométricos

$$
\left(\mathrm{Tc}^{\text {g-bio }}=367+158 \times \log \left[d_{\Theta_{\text {bio }}-\mu m}\right]^{\circ} \mathrm{C} ; \mathrm{r}^{2}=0.7,2 \sigma= \pm 34^{\circ} \mathrm{C}\right)
$$

e subsequente normalização a biotita $=100 \mu \mathrm{m}$. O valor

$$
T_{c\left(\Theta_{\text {bio }}=100 \mu m\right)}^{g r-b i o}=683 \pm 34^{\circ} \mathrm{C}
$$

calculado corresponde a taxas de resfriamento $\sim 20-300^{\circ} \mathrm{C} / \mathrm{Ma}$, no intervalo $750^{\circ} \mathrm{C}-550^{\circ} \mathrm{C}$ (Fig. 2), implicando rápida exumação inicial do terreno metamórfico estudado.

Taxas de resfriamento geocronológicas

Estudos geocronológicos prévios realizados em escala regional (Siga Jr et al. 1982), suportam evolução poli-orogênica, evidenciando núcleos de embasamento Transamazônico $(\sim 2 \mathrm{Ga})$ parcialmente reativados durante o Ciclo Brasiliano. Datações $\mathrm{U} / \mathrm{Pb}$ em zircão indicam instalação crustal de magmas graníticos entre 625 e 490 Ma (Noce et al. 2000, Pedrosa Soares \& Wiedemann-Leonardos 2000, Pedrosa Soares et al. 2001, Silva et al. 2002, Medeiros et al. 2003), enquanto que as idades $\mathrm{K} / \mathrm{Ar}$ obtidas nos gnaisses migmatíticos objeto deste estudo, sugerem que as rochas metamórficas teriam ascendido através das isotérmicas $550^{\circ} \mathrm{C}$ $300^{\circ} \mathrm{C}$ há 500 - 450 Ma (Siga Jr et al. 1982).
Nesta seção apresentam-se resultados preliminares da investigação geocronológica sistemática na Faixa de Dobramentos Araçuaí. A análise incidiu sobre 10 amostras (Tabelas 1e 2), incluindo leucossomas garanadíferos (UT-33cl, UT-33e, CO-9, CO-110: feldspato potássico + plagioclásio + biotita + granada + quartzo) e restitos granulíticos (UT-32, UT-32a, UT-32b, UT-32c, CO-57, PINH: granada + cordierita + feldspato potássico + plagioclásio + sillimanita + biotita + quartzo). Foram obtidas 9 novos dados isotópicos $\mathrm{Sm} / \mathrm{Nd}, \mathrm{Rb} / \mathrm{Sr}$ e Ar/Ar em granada, plagioclásio, biotita, feldspato potássico, e rocha total (Figs. 3, 4 e 5)

A Tabela 3 e a figura 7 sintetizam os dados geocronológicos obtidos, com indicação também das temperaturas de fechamento características (Mezger et al. 1992, Heaman \& Parrish 1991, Lovera et al. 1997, MacDougall \& Harrison 1999) dos sistemas analisados. Em vista da temperatura máxima $\left(\mathrm{T}_{\operatorname{mix}}=820 \pm 30^{\circ} \mathrm{C}\right)$ experimentada pelas rochas regionais, a datação $\mathrm{Rb} / \mathrm{Sr}$ - rocha total (530 $\pm 27 \mathrm{Ma}$; Tabela 1, Fig. 5), obtida em diferenciados migmatíticos da Pedreira Mascarenhas (Baixo-Guandu) é interpretada como devida à reorganização mineralógica provocada pelo metamorfismo, implicando na homogeneização isotópica do $\mathrm{Sr}$ nos sistemas de rocha total, na escala mesoscópica de afloramento. Pelo contrário, as isócronas internas $\mathrm{Rb} / \mathrm{Sr}, \mathrm{Sm} / \mathrm{Nd}$ e as datações $\mathrm{Ar} / \mathrm{Ar}$ devem refletir idades de resfriamento subsequente, correspondendo ao tempo em que as rochas resfriaram abaixo das respectivas temperaturas de fechamento (Tabela 2). Em conformidade, as médias ponderadas das idades obtidas em granada, plagioclásio e biotita são $475 \pm 6 \mathrm{Ma}, 473 \pm 8 \mathrm{Ma}$ e $470 \pm 2 \mathrm{Ma}$, respectivamente. As amostras de feldspato potássico produziram datações mais jovens e um espectro de idades mais largo, (440-419 Ma; Tabela 2), refletindo as complexidades da difusão de Ar na estrutura deste mineral (Lovera et al. 1997, MacDougall \& Harrison 1999).

Considerando que existem diferenças apreciáveis entre as temperaturas de fechamento dos equilíbrios isotópicos ${ }^{143} \mathrm{Nd} /{ }^{144} \mathrm{Nd}$ granada, ${ }^{87} \mathrm{Sr} /{ }^{86} \mathrm{Sr}$ - plagioclásio e ${ }^{40} \mathrm{Ar} /{ }^{39} \mathrm{Ar}$-biotita (Tabela 3), é notável que as idades obtidas nesses minerais sejam tão semelhantes. Pelos valores das idades aparentes encontradas, é necessário reconhecer que o tempo decorrido entre o fechamento do sistema $\mathrm{Sm} / \mathrm{Nd}$ na granada e o isolamento de Ar na biotita deve ter sido necessariamente pequeno. Embora os dados geocronológicos careçam da necessária precisão, se for assumida uma diferença temporal da ordem de $5 \mathrm{Ma}$ entre as idades aparentes $\mathrm{Sm} / \mathrm{Nd}$ da granada e $\mathrm{Ar} / \mathrm{Ar}$ da biotita, isto seria consistente com uma taxa de resfriamento linear $\approx 60^{\circ} \mathrm{C} / \mathrm{Ma}$, de $\sim 600^{\circ} \mathrm{Ca} \sim 300^{\circ} \mathrm{C}$ (Fig. 7). AT $<300^{\circ} \mathrm{C}$, as datações $\mathrm{Ar} / \mathrm{Ar}$ em feldspato potássico sugerem declínio significativo nas taxas de resfriamento (Fig. 7). Em contraste, a $\mathrm{T}>600^{\circ} \mathrm{C}$, os dados geocronológicos não subsidiam a história térmica do terreno metamórfico. Contudo, as taxas de resfriamento petrológico, calculadas em condições mais próximas do pico metamórfico $\left(550^{\circ} \mathrm{C} \leq \mathrm{T} \leq 750^{\circ} \mathrm{C}\right.$; fig. 2$)$, complementam a informação geocronológica de alta temperatura. Os resultados obtidos via modelamento difusivo, granada-biotita, variam de $\sim 20$ a $300^{\circ} \mathrm{C} / \mathrm{Ma}$, consistentes com os dados geocronológicos. Em particular, o elevado ajuste da regressão linear

$$
\mathrm{T}_{\mathrm{C}}^{\mathrm{gr}-\mathrm{bio}}=\mathrm{f}\left[\log \left(\Theta^{\text {bio }}\right)\right]
$$

(Fig. 2), indica (Tassinari et al. 2004) que as rochas metamórficas resfriaram mais rapidamente $\left(>60^{\circ} \mathrm{C} / \mathrm{Ma}\right)$ durante os primeiros 100 $-150^{\circ} \mathrm{C}\left(750^{\circ} \mathrm{C} \rightarrow 650-600^{\circ} \mathrm{C}\right)$, como ilustra a figura 7. De acordo com estes dados, o regime termocronológico de alta temperatura sugere, por extrapolação dos resultados geocronológicos a partir de $600{ }^{\circ} \mathrm{C} / 475 \pm 6 \mathrm{Ma}$, usando taxas de resfriamento $60-300^{\circ} \mathrm{C} /$ 
Tabela 1 - Dados analíticos Rb-Sr e Sm-Nd. Análises efetuadas no Centro de Pesquisas Geocronológicas da Universidade de São Paulo, cujos procedimentos constam de Kawashita (1972, modificado) e Sato et. al. (1995).

\begin{tabular}{lccccccc}
\hline Amostra & Material & $\mathrm{Sm}(\mathbf{p p m})$ & $\mathbf{N d}(\mathbf{p p m})$ & ${ }^{147} \mathrm{Sm} /{ }^{144} \mathrm{Nd}$ & $2 \sigma$ & ${ }^{143} \mathbf{N d} /{ }^{144} \mathbf{N d}$ & $2 \sigma$ \\
\hline CO-9 & r.total & 8.038 & 32.617 & 0.1490 & 0.0005 & 0.512106 & 0.000012 \\
CO-9 & gr & 5.179 & 3.212 & 0.9751 & 0.0042 & 0.514664 & 0.000018 \\
CO-110 & r.total & 12.635 & 72.063 & 0.1060 & 0.0004 & 0.512009 & 0.000013 \\
CO-110 & gr & 10.378 & 4.370 & 1.4362 & 0.0056 & 0.516166 & 0.000015 \\
\hline & & $\mathbf{R b}(p p m)$ & $\mathbf{S r}(p p m)$ & ${ }^{87} \mathbf{R b} /{ }^{86} \mathbf{S r}$ & $2 \sigma$ & ${ }^{87} \mathbf{S r} /{ }^{86} \mathbf{S r}$ & $2 \sigma$ \\
\hline UT-32 & r.total & 125.6 & 381.3 & 0.955 & 0.017 & 0.719099 & 0.000124 \\
UT-32a & r.total & 83.7 & 350.3 & 0.692 & 0.004 & 0.717137 & 0.000028 \\
UT-32b & r.total & 154.9 & 329.1 & 1.365 & 0.010 & 0.722158 & 0.000068 \\
UT-32c & r.total & 85.9 & 341.2 & 0.730 & 0.010 & 0.717639 & 0.000075 \\
UT-33cl & r.total & 136.1 & 302.9 & 1.302 & 0.018 & 0.721910 & 0.000087 \\
UT-33e & r.total & 157.3 & 341.8 & 1.333 & 0.009 & 0.722071 & 0.000117 \\
PINH & r.total & 168.9 & 140.5 & 3.493 & 0.046 & 0.746049 & 0.000022 \\
PINH & plag & 64.8 & 202.2 & 0.929 & 0.005 & 0.728760 & 0.000058 \\
\hline
\end{tabular}

Tabela 3 - Síntese dos dados geocronológicos associados às respectivas temperaturas de fechamento.

\begin{tabular}{lccccc}
\hline Amostra & Método & Análise & Idade Ma & $2 \sigma$ & Tc $^{\circ} \mathrm{C}$ \\
\hline MASC & $\mathrm{Rb} / \mathrm{Sr}$ & r.total & 530 & 27 & $750-800$ \\
$\mathrm{CO}-9$ & $\mathrm{Sm} / \mathrm{Nd}$ & gr - r.total & 473 & 6 & 600 \\
$\mathrm{CO}-110$ & $\mathrm{Sm} / \mathrm{Nd}$ & gr - r.total & 477 & 6 & 600 \\
$\mathrm{PINH}$ & $\mathrm{Rb} / \mathrm{Sr}$ & plag-r.total & 473 & 8 & 500 \\
$\mathrm{CO}-57$ & $\mathrm{Ar} / \mathrm{Ar}$ & biotita & 471 & 3 & 300 \\
$\mathrm{CO}-110$ & $\mathrm{Ar} / \mathrm{Ar}$ & biotita & 470 & 1 & 300 \\
$\mathrm{CO}-9$ & $\mathrm{Ar} / \mathrm{Ar}$ & $\mathrm{FK}$ & 420 & 3 & 200 \\
$\mathrm{CO}-57$ & $\mathrm{Ar} / \mathrm{Ar}$ & $\mathrm{FK}$ & 419 & 5 & 200
\end{tabular}

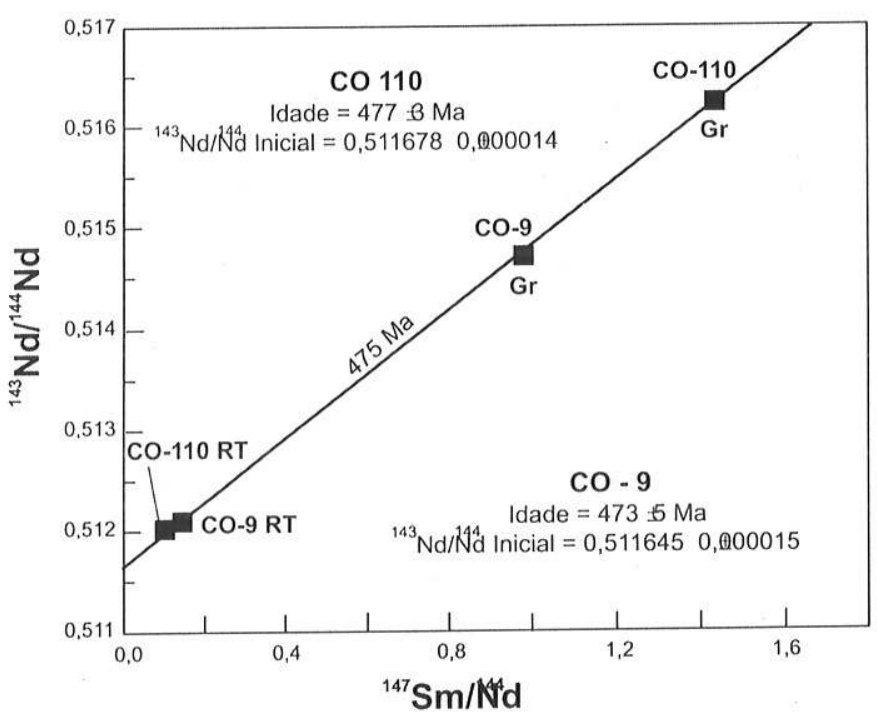

Figura 3 - Diagrama isocrônico Sm-Nd para o par granadarocha total das amostras CO-9 e CO-110. Idade calculada como programa ISOPLOT (Ludwig 1999).

$\mathrm{Ma}$, que as rochas analisadas permaneceram sob condições de alto grau metamórfico $\left(\mathrm{T} \sim 750^{\circ} \mathrm{C}\right.$ ) até $478-476$ ( \pm 6$) \mathrm{Ma}$ (Fig. 7).

A integração dos resultados termocronológicos ilustrada na figura 7, mostra que a história térmica das rochas metamórficas na Faixa de Dobramentos Araçuaí é caracterizada por resfriamento

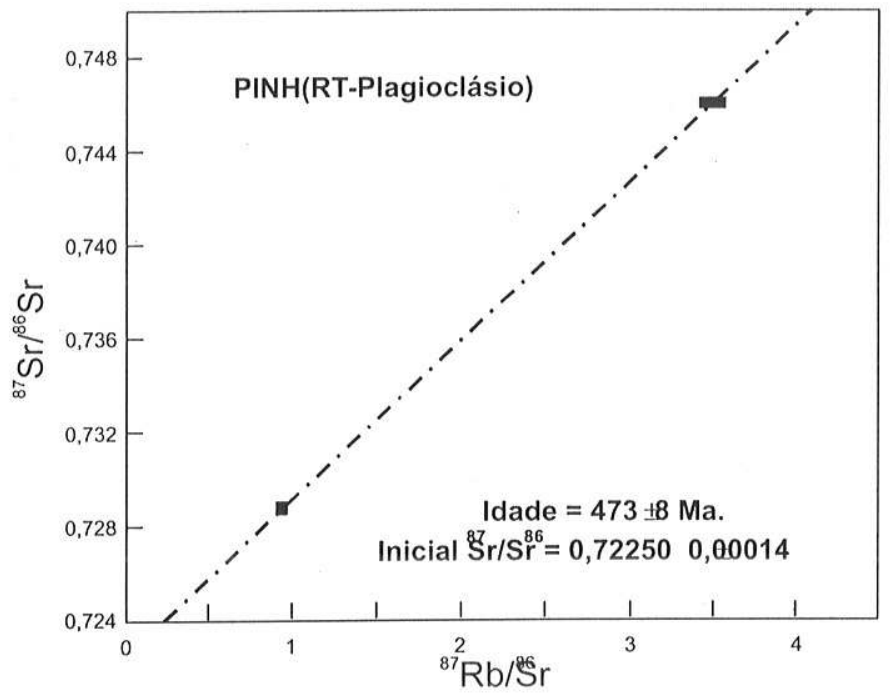

Figura 4 - Diagrama isocrônico Rb-Sr para o par plagioclásiorocha total da amostra PINH. Idade calculada com o programa ISOPLOT (Ludwig 1999).

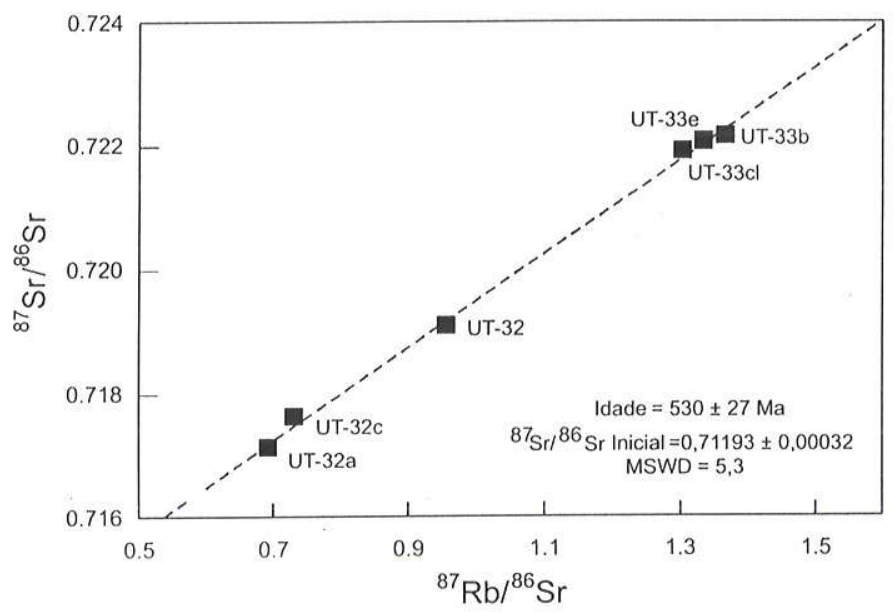

Figura 5 - Diagrama isocrônico $\mathrm{Rb}$-Sr em rocha total para as amostras UT-32 e UT-33, da Pedreira Mascarenhas (Baixo Guandú). Idade calculada com o programa ISOPLOT (Ludwig 1999). 
CO-57 / Biotita

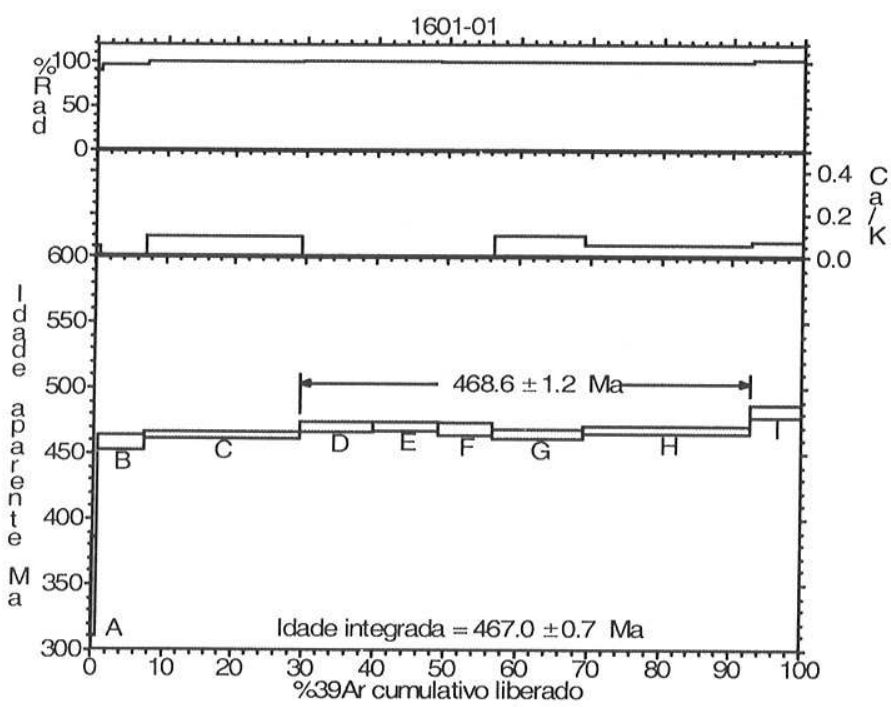

1601-02
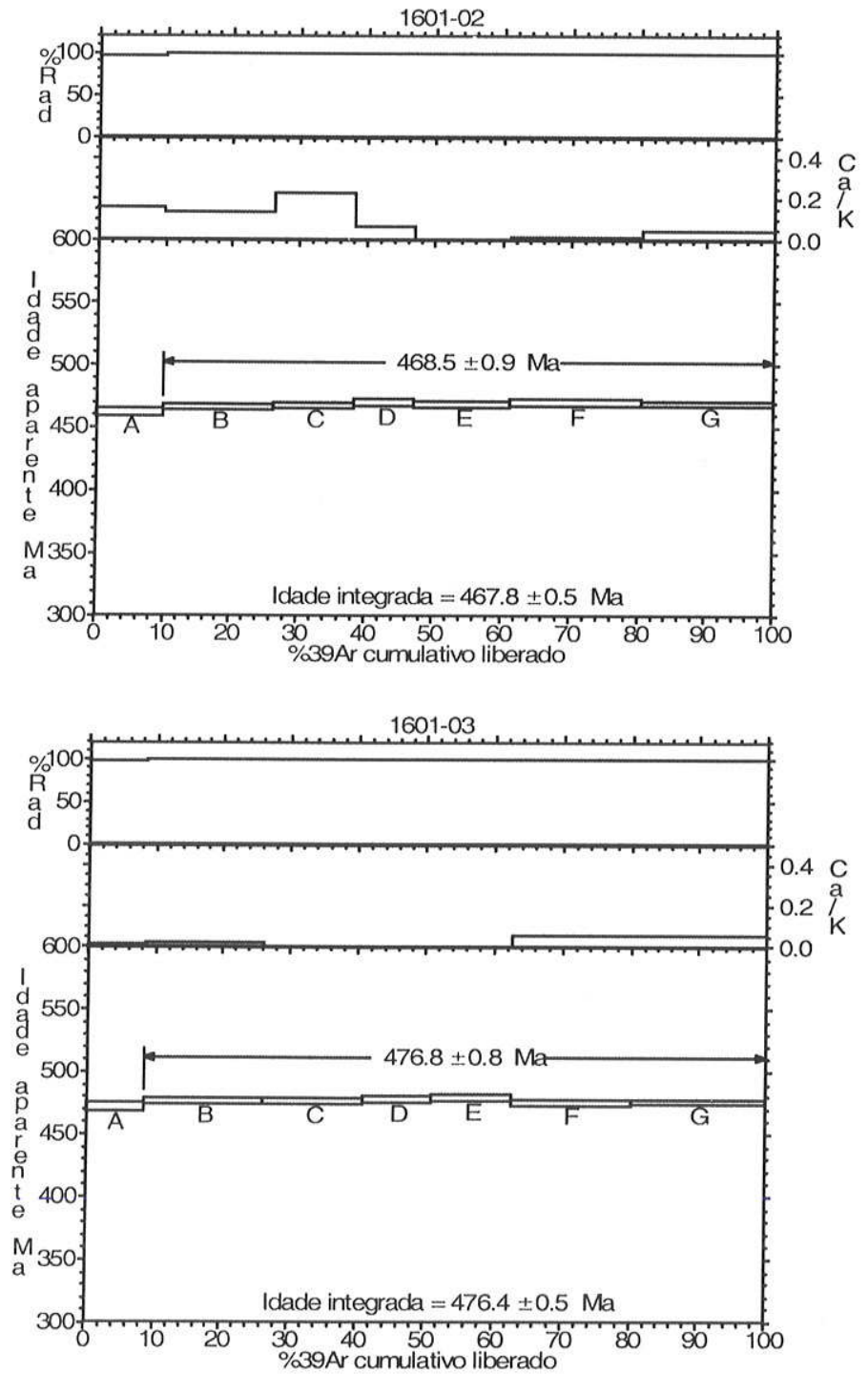

CO-110/ Biotita
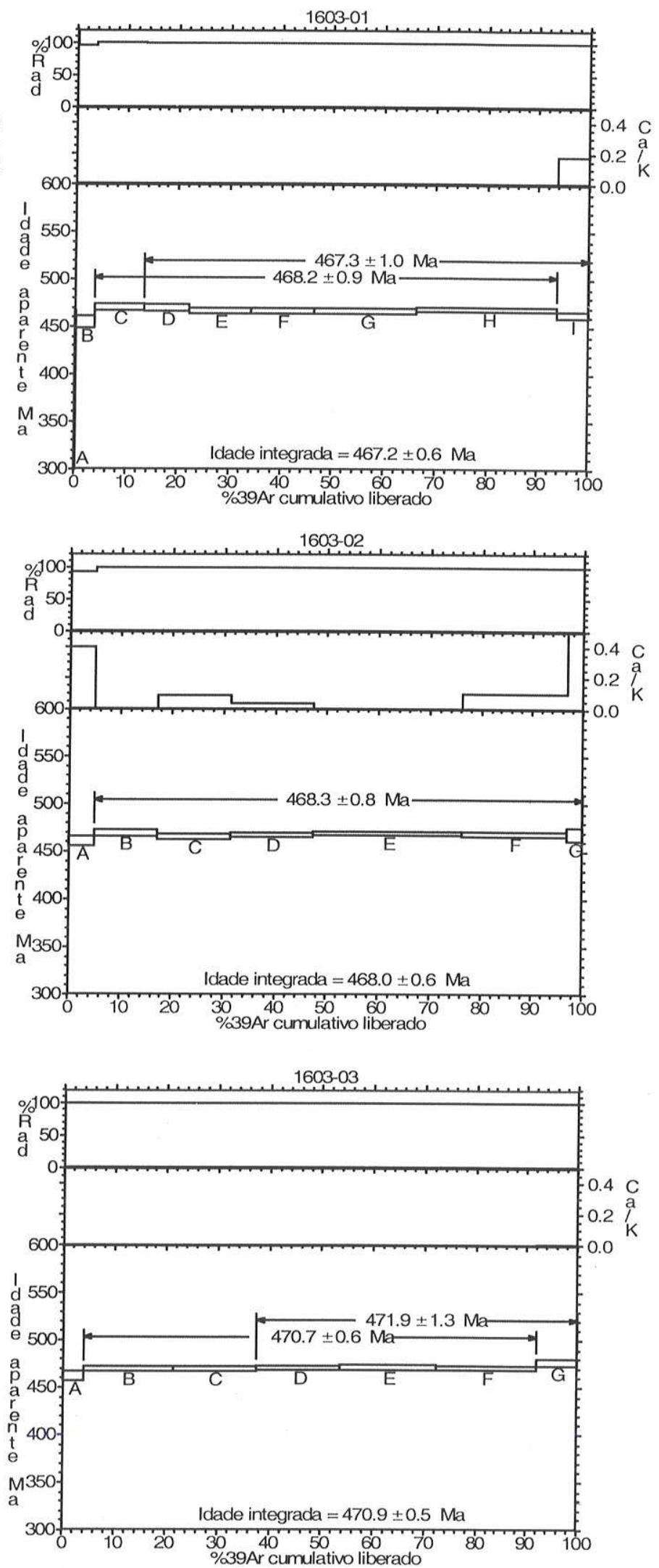

Figura $6 \mathrm{~A}$ - Diagramas de espectro de aquecimento por etapas ${ }^{40} \mathrm{Ar}-{ }^{30} \mathrm{Ar}$, mostrando idades Plateau Ar-Ar em biotita das amostras CO-57, $C O-110$. 
CO-9 / K-feldspar

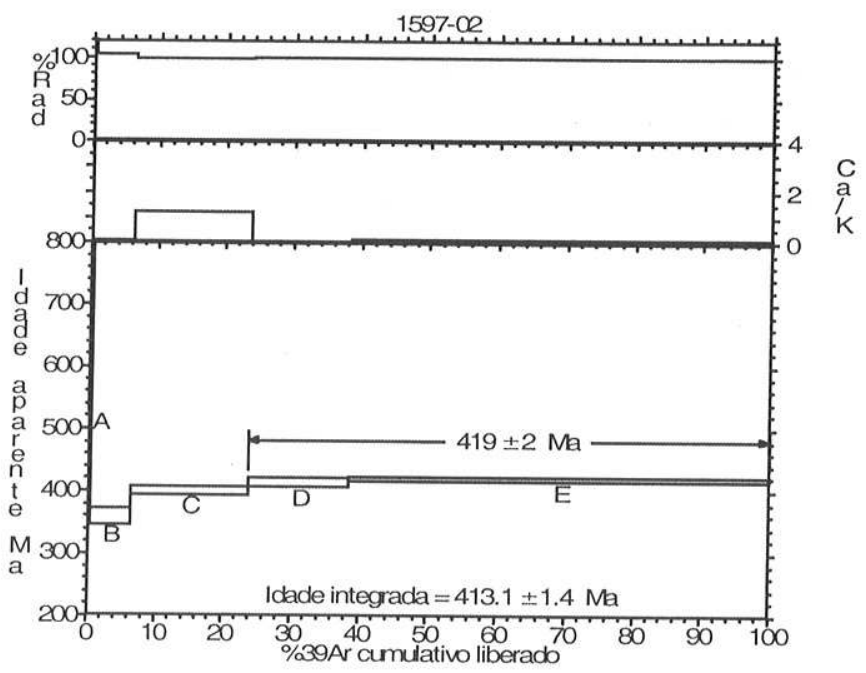

1597-03 - Fusão total

Idade: $419.08 \pm 1.15 \mathrm{Ma}$

CO-57 / K-feldspar

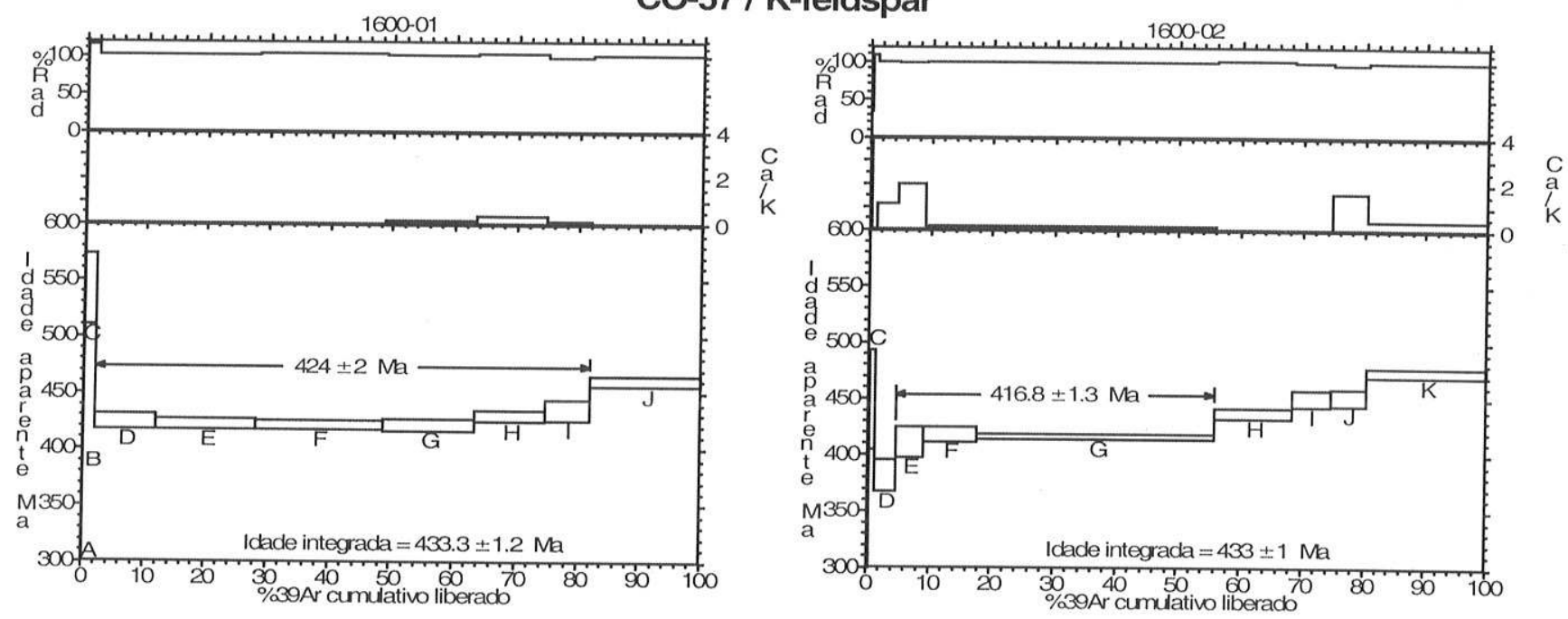

CO-110 / K-feldspar
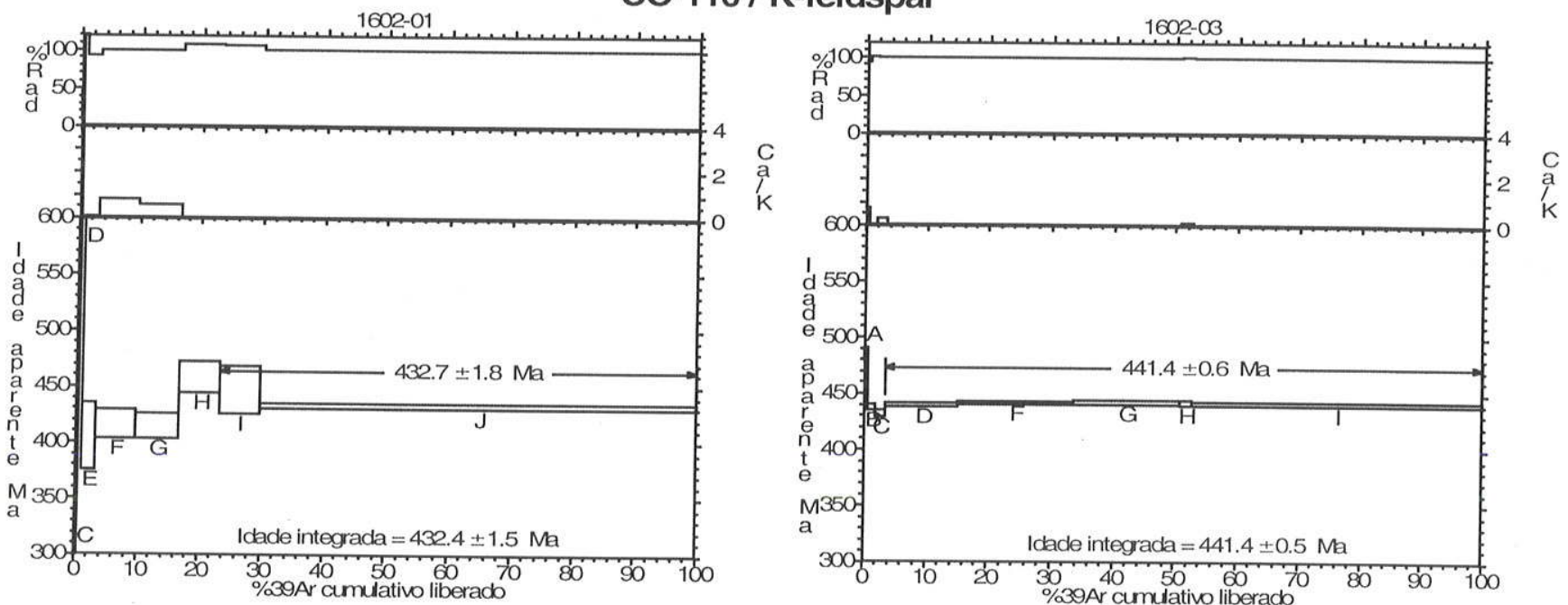

Figura 6 B - Diagramas de espectro de aquecimento por etapas ${ }^{40} \mathrm{Ar}-{ }_{-39} \mathrm{Ar}$, mostrando idades Plateau Ar-Ar em feldspato potássico das amostras $\mathrm{CO}-9, \mathrm{CO}-57$ e $\mathrm{CO}-110$. 


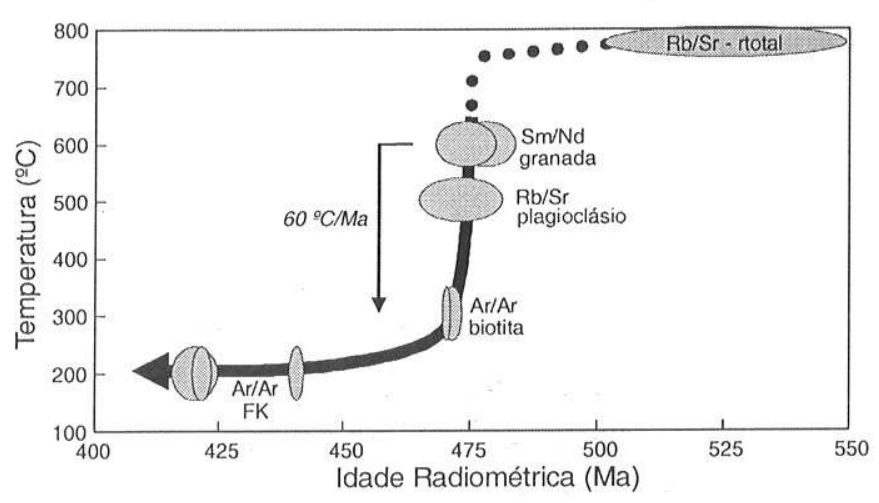

Figura 7 - Temperatura - tempo: história térmica dos gnaisses migmatíticos (vide texto).

marcadamente descontínuo. Após atingir o pico térmico ( 530 $\mathrm{Ma})$, durante longo tempo $(\sim 530 \rightarrow \sim 480 \mathrm{Ma})$, o terreno metamórfico teria arrefecido muito lentamente, sucedendo-se um curto período $(\leq 10 \mathrm{Ma})$ de resfriamento $\left(\sim 750 \rightarrow \sim 300^{\circ} \mathrm{C}\right)$ mais rápido $\left(\geq 60^{\circ} \mathrm{C} / \mathrm{Ma}\right)$, provavelmente refletindo a maior eficiência dos esforços tectônicos durante a exumação. Forte desaceleração nas taxas de resfriamento a $\mathrm{T}<300{ }^{\circ} \mathrm{C}\left(\sim 2{ }^{\circ} \mathrm{C} / \mathrm{Ma}\right)$ marca nova descontinuidade na evolução termocronológica, indicando que a dominância do regime térmico advectivo, de origem tectônica, teria cessado há $470 \mathrm{Ma}$.

DISCUSSÃOE CONCLUSÕES As condições máximas deP-T metamórfico a que estiveram submetidos os gnaisses migmatíticos da Faixa de Dobramentos Araçuaí, na área de estudo, são definidas pelos dados geotermobarométricos obtidos neste estudo, a $6.5 \pm 0.5 \mathrm{kbar}, 820 \pm 30^{\circ} \mathrm{C}$. A abundância de leucossomas e texturas de reação indicam que eventos de fusão parcial, desidratante teriam atuado nestas rochas. Em conjunto com o padrão de zoneamento composicional, as observações petrográficas sugerem que a cristalização tardia de cordierita + feldspato potássico + biotita, e a intensa reabsorção de granada, teriam sido induzidas por reações retrogressivas sob alta-temperatura, refletindo a solidificação in situ dos líquidos silicatados não segregados. A análise textural indica que as condições de pico metamórfico e fusão parcial teriam evoluído desde síncronos a tardios em relação à deformação responsável pelo desenvolvimento da foliação metamórfica.

As condições de máximo térmico, inferido da geotermometria $\left(820^{\circ} \mathrm{C}\right)$, foram elevadas relativamente à profundidade $(20-25$ km), implicando incremento do gradiente geotérmico em relação à geotérmica continental típica das regiões estáveis. O incremento da produção interna de calor e o relaxamento térmico resultantes de eventual sobre-espessamento tectônico, associado ao metamorfismo, são claramente inadequados para explicar as temperaturas observadas, sendo necessário recorrer a fontes de calor suplementares. De fato, o longo período de incubação sob alta temperatura, inferido da análise termocronológica, requer manutenção de alto fluxo termal numa região crustal relativamente estável, sendo implícito que o orógeno foi significativamente adelgaçado durante o tempo decorrido ( 40 - $70 \mathrm{Ma}$ ) entre o evento colisional (sobre-espessamento crustal) e a aquisição da estrutura térmica inerente ao pico metamórfico regional. Os corpos plutônicos da região poderiam constituir, localmente, fonte de calor apropriada. Contudo, o metamorfismo tem distribuição regional, não se justificando atribuir a fonte de calor a nenhuma intrusão em particular. Neste contexto, é significativo que os padrões geocronológico e geoquímico dos granitóides regionais indiquem incremento progressivo de componente mantélico nesses magmas durante o período 535 - 490 Ma (Ludka et al. 1998, Pedrosa Soares \& Wiedemann-Leonardos 2000, Martins et al. 2004), correspondendo aos estádios magmáticos pós-colisionais da evolução Brasiliana. Os resultados termocronológicos obtidos neste estudo sugerem que as rochas, da Faixa Araçuaí foram submetidas a condições de alto grau metamórfico entre $\sim 530$ Ma e $\sim 480$ Ma. Portanto, é possível que atividade magmática mantélica possa ter contribuído para a estrutura térmica observada. Delaminação litosférica e conseqüente ascensão do manto astenosférico, com acreção magmática na base da crosta (Kay \& Kay 1993), são características do re-equilíbrio gravitacional nos estádios póscolisionais em muitos orógenos. Este mesmo processo poderia ter sido responsável pelo incremento do fluxo calorífico durante o metamorfismo regional na Faixa Araçuaí, induzindo fusão parcial e elevação da geotérmica continental, como requerem os dados geotermobarométricos.

$\mathrm{O}$ modelamento da troca $\mathrm{Fe}-\mathrm{Mg}$ difusiva entre inclusões de biotita e granada hospedeira sugere taxas de resfriamento $\left(750^{\circ} \mathrm{C}\right.$ $\rightarrow 550{ }^{\circ} \mathrm{C}$ ) de $\sim 300-20^{\circ} \mathrm{C} / \mathrm{Ma}$, enquanto que os resultados geocronológicos indicam taxas de resfriamento $\left(600^{\circ} \mathrm{C} \rightarrow 300^{\circ} \mathrm{C}\right)$ de $\sim 60^{\circ} \mathrm{C} / \mathrm{Ma}$. O conjunto de dados obtidos por ambos os métodos é consistente com resfriamento rápido a partir de $\sim 480 \mathrm{Ma} \mathrm{(<}$ $\left.10 \mathrm{Ma} \mathrm{a} \geq 60^{\circ} \mathrm{C} / \mathrm{Ma}\right)$, a que se seguiu declínio acentuado das taxas de resfriamento entre $\sim 470-420 \mathrm{Ma}\left(\sim 2^{\circ} \mathrm{C} / \mathrm{Ma}\right)$. O período de resfriamento rápido corresponde, provavelmente, aos estádios iniciais de reajustamento termo-mecânico durante a evolução tarditectônica do orógeno. Reativação das estruturas ao longo de zonas de cisalhamento é consistente com a rápida exumação dos gnaisses migmatíticos e sua justaposição às unidades cratonizadas, mais frias, refletindo o processo de colapso orogênico (Pedrosa Soares \& Wiedemann-Leonardos 2000, Pedrosa Soares et al. 2001, Whittington et al. 2001). Finalmente, à medida que cessaram os esforços tectônicos tangenciais, a dissipação da instabilidade termo-gravitacional foi condicionada por transferência de calor conductiva e compensação isostática, como indica o declínio observado nas taxas de resfriamento.

Excedendo a problemática regional, a Faixa de Dobramentos Ribeira/Araçuaí é paradigmática na discussão dos conceitos da evolução secular do regime térmico de cadeias orogênicas e evidenciando a complexidade do problema. Dunlap (2000) sugere a existência de uma correlação inversa entre as idades de eventos orogênicos e as respectivas taxas de resfriamento. A ideia é simplese baseia-se na premissa de que nas cadeias antigas ( \pm compensadas isostaticamente) as unidades metamórficas profundas permaneceriam mais tempo sob condições P-T suficientemente próximas das temperaturas de fechamento isotópico, induzindo idades progressivamente mais recentes e, por isso, sugerindo taxas de resfriamento mais lentas. Contudo, investigações termocronológicas realizadas em vários segmentos da Faixa de Dobramentos Ribeira, com emprego dos mesmos métodos analíticos mostram um padrão bem mais complexo. No segmento São Sebastião-Bertioga, Dias Neto et al. (2000) demonstram que os gnaisses migmatíticos do Complexo Costeiro no Estado de São Paulo, atingiram condições de pico metamórfico na fácies granulíto: $\left(750^{\circ} \mathrm{C}, 5-6 \mathrm{kbar}\right)$ há $571 \pm 10 \mathrm{Ma}(\mathrm{U} / \mathrm{Pb}$-zircão), tendo posteriormente evoluído com uma taxa de resfriamento de $\sim 3^{\circ} \mathrm{C} / \mathrm{Ma}$, até $400^{\circ} \mathrm{C}$ há $471 \pm 8 \mathrm{Ma}$ (Rb/Sr: plag-bio).

No presente estudo sobre o segmento setentrional da Faixa 
de Dobramentos Ribeira (Faixa Araçuaí), evidenciam-se taxas de resfriamento que são claramente superiores $\left(\geq 60^{\circ} \mathrm{C} / \mathrm{Ma}\right)$, em rochas submetidas ao mesmo tipo de metamorfismo. Neste contexto, é particularmente significativo que a história térmica de baixa temperatura $\left(<400^{\circ} \mathrm{C}\right)$ no Complexo Costeiro (Dias Neto, comunicação pessoal, 2002) indique aceleração da exumação no intervalo 480 - $470 \mathrm{Ma}$, coincidindo com o climax tectonometamórfico a norte, o que é difícil de conciliar com a generalização das bases conceituais da hipótese Dunlap (2000). São, óbviamente, necessários estudos complementares detalhados em diferentes orógenos, com um espectro de idades apropriado, para caracterizar eventuais variações seculares no regime termotectônico.
Agradecimentos Publicação elaborada durante a licença sabática de JMunhá no Instituto de Geociências da USP com suporte da FAPESP(Processo 03/00027-4). É uma contribuição dos projetos de investigação PETROLOG (FCT-Portugal; POCTI/FEDER), Termocronologia em Modelação Tectonometamórfica (Cooperação Científica Internacional Brasil/Portugal- CAPES/ICCTI 042/ 99) e Zona Orogênica Brasiliana no sudeste do Brasil: Idades e Evolução Geodinâmica (Processo FAPESP03-00500-0) e ao Projeto (PRONEX n 41.96.0899.00) Geologia isotópica Aplicada na América do Sul.Os autores agradecem aos técnicos do CPGeo-IGC USP, em especial ao Artur Onoe pelo suporte analítico e aos revisores da RBG pelas sugestões ao manuscrito.

\section{Referências}

Berman R.G. 1988. Internally-consistent thermodynamic data for minerals in the system Na2O-K2O-CaO-MgO-FeO-Fe2O3SiO2-TiO2-H2O-CO2. J. Petrology., 29:445-522.

Berman R.G. 1990. Mixing properties of Ca-Mg-Fe-Mn garnets. Am. Mineral., 75:328-344.

Berman R.G. 1991. Thermobarometry using multiequilibrium calculations: a new technique with petrologic applications. Can. Mineral., 29:833-855.

Berman R.G. \& Aranovich I.Y. 1996. Optimized standard state and solution properties of minerals. I. Model calibration for olivine, orthopyroxene, cordierita, garnet and ilmenita in the system $\mathrm{FeO}-\mathrm{MgO}-\mathrm{CaO}-\mathrm{Al}_{2} \mathrm{O}_{3}-\mathrm{TiO}_{2}-\mathrm{SiO}_{2}$. Contrib. Mineral. Petrol., 126: $1-24$.

Chakraborty S. \& Ganguly J. 1992. Cation diffusion in aluminosilicate garnets - experimental determination in spessartine-almandine diffusion couples, evaluation of effective binary diffusion coefficients, and applications. Contrib. Mineral. Petrol., 111:74-86.

Dias Neto C.M., Munhá J., Palácios T., Tassinari C.C.G, RibeiroA. 2000. Tectonothermal evolution of the Costeiro Complex (São Sebastião - Bertioga; SE Brazil). i: petrological and geochronological constraints. In: IUGS. $31^{\text {st }}$ Intern. Geol. Congress (Rio-2000), CDROM abstracts.

Dodson M.H. 1973. Closure temperature in cooling geological and petrological systems. Contrib. Mineral.Petrol., 40:259-274.

Dunlap W.J. 2000. Nature's diffusion experiment: the cooling-rate cooling-age correlation. Geology. 28:139-142.

Ehlers K., Powell R., Stuwe K. 1994. The determination of cooling rate histories from garnet-biotite equilibrium. Am. Min.., 79:737-744.

Ferry J.M. \& Spear F.S. 1978. Experimental calibration of the partinioning of Fe and $\mathrm{Mg}$ between biotite and garnet. Contrib. Mineral. Petrol., 66:113-117.

Heaman L. \& Parrish R.R. 1991. U-Pb geochronology of accessory minerals. In: Applications of Radiogenic Isotope Systems in Problems in Geology. Mineralogical Association of Canada, Short Course Handbook 19, 59-102.

Kawashita K. 1972. O método Rb-Sr em rochas sedimentares, aplicação para as Bacias do Paraná e Amazonas. Tese de
Doutoramento, IG-USP, $111 \mathrm{p}$.

Lasaga A.G. .1979. Multicomponent exchange and diffusion in silicates. Geochim. Cosmochim. Acta, 43:455-469.

Lasaga A.G, Richardson S.M., Holland H.D. 1977. The mathematics of cation diffuson and exchange between silicate minerals during retrograde metamorphism. In: S.K. Saxena \& S. Battacharji (eds.) Energetics of Geological Processes (Springer), 354-387

LoveraO.M., Grove M., Harrison T.M., Mahon K. I. 1997. Systematic analysis of $\mathrm{K}$ feldspar 40Ar/39Ar step heating results: I. significance of activation energy determinations. Geochim. Cosmochim. Acta, 61:3171-3192.

Ludwig K. 1999. Isoplot/Ex. Berkeley Geochronological Center. Special Publication 1.

McDougall I. \& Harrison T.M. 1999. Geochronology and Thermochronology by the 40Ar/39Ar method. Oxford Univ. Press. London, 287 pp.

Pedrosa Soares A.C. \& Wiedemann-Leonardos C.M. 2000. Evolution of the Araçuai Belt and its connection to the Ribeira Belt, Eastern Brazil. In:U.G Cordani, E.J. Milani, A. Thomaz Filho, D.A. Campos (eds) - Tectonic Evolution of South America (31 ${ }^{\text {st }}$ International Geological Congress), 265-285.

Pedrosa Soares A.C., Noce, C.M., Wiedemann-Leonardos C.M., Pinto C.P. 2001. The Araçuaí - West Congo Orogen in Brazil: An overview of a confined orogen formed during Gondwanaland assembly. Prec. Res., 110 (1-4): 307-323

Robinson P. 1991. The eye of the petrographer, the mind of the petrologist. Am. Mineral., 76:1781-1810.

Sato K., Tassinari C. C.G., Kawashita K., Petronilho L. 1995. O método geocronológico Sm-Nd no IG-USP e suas aplicações. Anais Acad. Bras. de Ciências, 67(3): 313-336

Siga Jr O., Teixeira W., Cordani U.G., Kawashita K., Delhal J. 1982. O padrão geocronológico das rochas de alto grau na parte setentrional da Faixa Ribeira, a norte do Rio de Janeiro, Brasil. In: Congresso Latino Americano de Geologia, $5^{\circ}$, (Argentina), Actas, 349-369.

Spear F.S., Kohn M.J., Cheney J.T. 1999. P-T paths from anatectic pelites. Contrib. Mineral. Petrol., 134:17-32.

Spear F.S. \& Parrish R.R. 1996. Petrology and cooling rates of the 
Valhalla Complex, British Columbia, Canada. J. Petrology, 37:733-765.

Thompson A.B. 1982. Dehydration melting of pelitic rocks during anatexis. Am. J. Sci., 282:1567-1595.

\section{Manuscrito A-1510 \\ Recebido em \\ Revisão dos autores em \\ Revisão aceita em}

Tabela 2 - Dados analíticos Ar-Ar. Análises efetuadas no Centro de Pesquisas Geocronológicas da Universidade de São Paulo, cujos procedimentos de análises constam de Vasconcelos et. al. (2002).

\begin{tabular}{|c|c|c|c|c|c|c|c|c|c|c|c|c|}
\hline Amostra & Material & $\mathbf{N}^{\circ} \mathbf{L a b}$ & $\begin{array}{c}\text { Laser } \\
\text { (W) }\end{array}$ & $40 / 39$ & $38 / 39$ & $37 / 39$ & $36 / 39$ & $40 * / 39$ & $\% \operatorname{Rad}$ & $\begin{array}{c}\text { Ar40 } \\
\text { (mols) }\end{array}$ & $\begin{array}{c}\text { Idade } \\
\text { (Ma) }\end{array}$ & $\begin{array}{l} \pm(1 \mathrm{~s}) \\
(\mathrm{Ma}) \\
\end{array}$ \\
\hline \multirow[t]{24}{*}{$\mathrm{CO}-110$} & biotita & $1603-01 \mathrm{~A}$ & 0,3 & 30,7574 & $-0,0640$ & 0,0000 & $-0,0243$ & 37,9243 & 123,3 & $2,06 \mathrm{E}-16$ & 360,89 & 53,18 \\
\hline & & 1603-01B & 0,6 & 51,0145 & 0,0178 & 0,0000 & 0,0062 & 49,1733 & 96,4 & $8,17 \mathrm{E}-15$ & 455,39 & 3,08 \\
\hline & & $1603-01 C$ & 0,9 & 50,6572 & 0,0128 & 0,0000 & $-0,0014$ & 51,0798 & 100,8 & $2,08 \mathrm{E}-14$ & 470,92 & 1,68 \\
\hline & & 1603-01D & 1,2 & 51,0303 & 0,0147 & 0,0000 & 0,0002 & 50,9568 & 99,9 & $1,97 \mathrm{E}-14$ & 469,92 & 1,79 \\
\hline & & $1603-01 \mathrm{E}$ & 1,6 & 50,6022 & 0,0146 & 0,0000 & 0,0001 & 50,5732 & 99,9 & $2,60 \mathrm{E}-14$ & 466,81 & 1,60 \\
\hline & & $1603-01 \mathrm{~F}$ & 2,0 & 50,7155 & 0,0145 & 0,0000 & 0,0004 & 50,6066 & 99,8 & $2,68 \mathrm{E}-14$ & 467,08 & 1,43 \\
\hline & & $1603-01 G$ & 2,6 & 50,7777 & 0,0154 & 0,0000 & 0,0005 & 50,6159 & 99,7 & $4,38 \mathrm{E}-14$ & 467,15 & 1,37 \\
\hline & & $1603-01 \mathrm{H}$ & 3,8 & 50,8059 & 0,0150 & 0,0000 & 0,0002 & 50,7507 & 99,9 & $6,02 \mathrm{E}-14$ & 468,25 & 1,29 \\
\hline & & 1603-01I & 5,2 & 50,1685 & 0,0151 & 0,0911 & 0,0003 & 50,0916 & 99,8 & $1,36 \mathrm{E}-14$ & 462,89 & 1,99 \\
\hline & & $1603-02 \mathrm{~A}$ & 0,6 & 53,3951 & 0,0171 & 0,2054 & 0,0120 & 49,8631 & 93,4 & $1,26 \mathrm{E}-14$ & 461,02 & 2,82 \\
\hline & & 1603-02B & 1,0 & 51,5237 & 0,0147 & 0,0000 & 0,0019 & 50,9543 & 98,9 & $2,95 \mathrm{E}-14$ & 469,90 & 1,68 \\
\hline & & $1603-02 \mathrm{C}$ & 1,6 & 50,8201 & 0,0151 & 0,0434 & 0,0012 & 50,4685 & 99,3 & $3,42 \mathrm{E}-14$ & 465,96 & 1,37 \\
\hline & & 1603-02D & 2,2 & 50,9076 & 0,0147 & 0,0197 & 0,0007 & 50,6936 & 99,6 & $3,83 \mathrm{E}-14$ & 467,79 & 1,24 \\
\hline & & $1603-02 \mathrm{E}$ & 2,9 & 50,9431 & 0,0143 & 0,0000 & 0,0002 & 50,8734 & 99,9 & $6,97 \mathrm{E}-14$ & 469,25 & 0,95 \\
\hline & & $1603-02 \mathrm{~F}$ & 3,6 & 50,8897 & 0,0146 & 0,0506 & 0,0005 & 50,7558 & 99,7 & $4,95 \mathrm{E}-14$ & 468,29 & 1,11 \\
\hline & & $1603-02 \mathrm{G}$ & 5,2 & 50,7583 & 0,0130 & 0,3176 & 0,0001 & 50,7500 & 100,0 & $7,47 \mathrm{E}-15$ & 468,25 & 3,56 \\
\hline & & $1603-03 \mathrm{~A}$ & 0,6 & 50,7233 & 0,0158 & 0,0000 & 0,0024 & 50,0001 & 98,6 & $1,06 \mathrm{E}-14$ & 462,14 & 2,45 \\
\hline & & 1603-03B & 1,0 & 51,0169 & 0,0142 & 0,0000 & 0,0002 & 50,9562 & 99,9 & $4,61 \mathrm{E}-14$ & 469,92 & 1,11 \\
\hline & & $1603-03 \mathrm{C}$ & 1,6 & 51,1767 & 0,0152 & 0,0000 & 0,0006 & 50,9950 & 99,6 & $4,23 \mathrm{E}-14$ & 470,24 & 1,16 \\
\hline & & 1603-03D & 2,2 & 50,9930 & 0,0145 & 0,0000 & $-0,0003$ & 51,0913 & 100,2 & $4,30 \mathrm{E}-14$ & 471,02 & 1,18 \\
\hline & & 1603-03E & 2,8 & 51,1708 & 0,0145 & 0,0000 & 0,0000 & 51,1799 & 100,0 & $4,93 \mathrm{E}-14$ & 471,74 & 1,30 \\
\hline & & $1603-03 \mathrm{~F}$ & 3,6 & 51,0912 & 0,0146 & 0,0000 & 0,0001 & 51,0708 & 100,0 & $5,24 \mathrm{E}-14$ & 470,85 & 1,16 \\
\hline & & 1603-03G & 5,2 & 52,0405 & 0,0152 & 0,0054 & 0,0009 & 51,7754 & 99,5 & $2,13 \mathrm{E}-14$ & 476,56 & 1,73 \\
\hline & & & & & & & & Idade méd & ia pond & erada (2s): & 469,2 & 1,3 \\
\hline \multirow[t]{17}{*}{ CO-9 } & feldspato & $1597-01 \mathrm{~A}$ & 0,4 & 1121,9160 & $-0,4632$ & 0,0000 & 0,4915 & 976,6198 & 87,0 & $5,34 \mathrm{E}-16$ & - & - \\
\hline & & 1597-01B & 0,7 & 5895,3960 & $-5,8327$ & 0,0000 & $-0,9000$ & 6160,7230 & 104,5 & $7,78 \mathrm{E}-16$ & - & - \\
\hline & & $1597-01 \mathrm{C}$ & 1,1 & 113,4421 & $-0,2158$ & 0,0000 & $-0,1535$ & 158,7675 & 140,0 & $2,82 \mathrm{E}-16$ & 1183,50 & 131,20 \\
\hline & & 1597-01D & 1,5 & 54,2559 & $-0,0251$ & 0,0000 & 0,0756 & 31,9085 & 58,8 & $3,04 \mathrm{E}-16$ & 308,24 & 68,47 \\
\hline & & $1597-01 \mathrm{E}$ & 2,0 & 53,5123 & $-0,0003$ & 0,0000 & 0,0712 & 32,4714 & 60,7 & $2,76 \mathrm{E}-16$ & 313,23 & 68,30 \\
\hline & & $1597-01 \mathrm{~F}$ & 2,6 & 52,3888 & $-0,1478$ & 0,0000 & $-0,0974$ & 81,1658 & 154,9 & $2,90 \mathrm{E}-16$ & 699,89 & 56,86 \\
\hline & & 1597-01G & 3,3 & 46,3848 & $-0,0270$ & 1,6303 & 0,0147 & 42,2206 & 90,9 & $3,06 \mathrm{E}-16$ & 397,57 & 46,83 \\
\hline & & $1597-01 \mathrm{H}$ & 4,1 & 47,6679 & $-0,0550$ & 0,0000 & $-0,0609$ & 65,6648 & 137,8 & $3,04 \mathrm{E}-16$ & 585,55 & 47,72 \\
\hline & & $1597-01 \mathrm{I}$ & 4,8 & 61,9551 & $-0,1695$ & 0,0000 & $-0,1789$ & 114,7921 & 185,3 & $2,24 \mathrm{E}-16$ & 925,50 & 74,29 \\
\hline & & $1597-01 \mathrm{~J}$ & 5,2 & 48,3458 & 0,0167 & 0,9780 & 0,0167 & 43,5088 & 89,9 & $1,58 \mathrm{E}-15$ & 408,42 & 10,83 \\
\hline & & $1597-02 \mathrm{~A}$ & 1,1 & 47,7440 & $-0,0620$ & 0,0000 & $-0,0953$ & 75,9087 & 159,0 & $1,83 \mathrm{E}-16$ & 661,92 & 66,99 \\
\hline & & $1597-02 \mathrm{~B}$ & 2,0 & 36,7863 & 0,0034 & 0,0153 & $-0,0031$ & 37,7084 & 102,5 & $1,68 \mathrm{E}-15$ & 359,02 & 6,07 \\
\hline & & $1597-02 \mathrm{C}$ & 3,5 & 43,3893 & 0,0139 & 0,6183 & 0,0035 & 42,4300 & 97,8 & $5,75 \mathrm{E}-15$ & 399,33 & 3,34 \\
\hline & & $1597-02 \mathrm{D}$ & 5,0 & 44,5533 & 0,0103 & 0,0000 & 0,0010 & 44,2659 & 99,4 & $5,04 \mathrm{E}-15$ & 414,77 & 3,61 \\
\hline & & $1597-02 \mathrm{E}$ & 5,2 & 44,7970 & 0,0112 & 0,0677 & $-0,0001$ & 44,8467 & 100,1 & $2,12 \mathrm{E}-14$ & 419,62 & 1,63 \\
\hline & & $1597-03$ & 5,2 & 44,8639 & 0,0117 & 0,0029 & 0,0003 & 44,7820 & 99,8 & $2,63 \mathrm{E}-14$ & 419,08 & 1,15 \\
\hline & & & & & & & & \multicolumn{3}{|c|}{ Idade média ponderada $(2 \mathrm{~s})$ : } & 419 & 2 \\
\hline
\end{tabular}


Tabela 3 - (Continuação).

\begin{tabular}{|c|c|c|c|c|c|c|c|c|c|c|c|}
\hline Amostra Material & $\mathbf{N}^{\prime \prime}$ Lab & $\begin{array}{c}\text { Laser } \\
\text { (W) }\end{array}$ & $40 / 39$ & $38 / 39$ & $37 / 39$ & $36 / 39$ & $40 * / 39$ & $\% \operatorname{Rad}$ & $\begin{array}{r}\text { Ar40 } \\
(\mathrm{mols})\end{array}$ & $\begin{array}{c}\text { Idade } \\
\text { (Ma) }\end{array}$ & $\begin{array}{l} \pm(1 \mathrm{~s}) \\
(\mathrm{Ma})\end{array}$ \\
\hline \multirow[t]{31}{*}{$\mathrm{CO}-57$} & $1600-01 \mathrm{~A}$ & 0,4 & 78,2974 & $-0,1674$ & 10,5849 & 0,3433 & $-22,4988$ & - & - & - & - \\
\hline & 1600-01B & 0,7 & 40,0156 & $-0,1527$ & 0,0000 & $-0,1226$ & 76,2217 & 190,5 & $8,74 \mathrm{E}-17$ & 664,20 & 133,29 \\
\hline & $1600-01 C$ & 1,1 & 52,3565 & $-0,0078$ & 0,0000 & $-0,0260$ & 60,0383 & 114,7 & $1,20 \mathrm{E}-15$ & 542,19 & 15,67 \\
\hline & $1600-01 \mathrm{D}$ & 1,5 & 45,0893 & 0,0128 & 0,0000 & $-0,0010$ & 45,3945 & 100,7 & $5,89 \mathrm{E}-15$ & 424,19 & 3,36 \\
\hline & $1600-01 \mathrm{E}$ & 2,0 & 44,7989 & 0,0099 & 0,0117 & $-0,0013$ & 45,1938 & 100,9 & $9,57 \mathrm{E}-15$ & 422,52 & 2,28 \\
\hline & $1600-01 \mathrm{~F}$ & 2,6 & 43,9904 & 0,0093 & 0,0043 & $-0,0038$ & 45,1128 & 102,6 & $1,18 \mathrm{E}-14$ & 421,84 & 2,01 \\
\hline & $1600-01 G$ & 3,3 & 44,8647 & 0,0107 & 0,0866 & $-0,0006$ & 45,0576 & 100,4 & $8,59 \mathrm{E}-15$ & 421,38 & 2,54 \\
\hline & $1600-01 \mathrm{H}$ & 4,1 & 45,0635 & 0,0082 & 0,1707 & $-0,0033$ & 46,0614 & 102,2 & $6,84 \mathrm{E}-15$ & 429,74 & 2,84 \\
\hline & $1600-011$ & 4,8 & 47,7808 & 0,0159 & 0,0531 & 0,0038 & 46,6690 & 97,7 & $4,20 \mathrm{E}-15$ & 434,77 & 4,62 \\
\hline & $1600-01 \mathrm{~J}$ & 5,2 & 48,9931 & 0,0094 & 0,0009 & $-0,0028$ & 49,8143 & 101,7 & $1,15 \mathrm{E}-14$ & 460,63 & 2,43 \\
\hline & $1600-02 \mathrm{~A}$ & 1,0 & 32,4715 & 0,2296 & 7,7777 & 0,1723 & $-17,8943$ & - & - & - & - \\
\hline & $1600-02 B$ & 1,6 & 45,7958 & 0,1711 & 5,9254 & 0,1028 & 15,9713 & 34,7 & $1,18 \mathrm{E}-16$ & 160,86 & 132,36 \\
\hline & $1600-02 \mathrm{C}$ & 2,2 & 44,5511 & $-0,0051$ & 0,0000 & $-0,0127$ & 48,3129 & 108,4 & $6,34 \mathrm{E}-16$ & 448,33 & 22,06 \\
\hline & 1600-02D & 2,8 & 40,3167 & 0,0052 & 0,5859 & 0,0002 & 40,3221 & 100,0 & $2,20 \mathrm{E}-15$ & 381,45 & 7,00 \\
\hline & $1600-02 \mathrm{E}$ & 3,5 & 45,0508 & 0,0143 & 1,0078 & 0,0044 & 43,8578 & 97,3 & $3,16 \mathrm{E}-15$ & 411,35 & 6,79 \\
\hline & $1600-02 \mathrm{~F}$ & 4,8 & 44,5742 & 0,0104 & 0,0943 & $-0,0002$ & 44,6461 & 100,2 & $6,21 \mathrm{E}-15$ & 417,95 & 3,06 \\
\hline & $1600-02 G$ & 5,2 & 44,7200 & 0,0124 & 0,0785 & 0,0007 & 44,5082 & 99,5 & $2,74 \mathrm{E}-14$ & 416,80 & 1,18 \\
\hline & $1600-02 \mathrm{H}$ & 2,5 & 46,6256 & 0,0124 & 0,0062 & $-0,0013$ & 46,9996 & 100,8 & $9,28 \mathrm{E}-15$ & 437,51 & 2,40 \\
\hline & $1600-02 \mathrm{I}$ & 3,0 & 48,6268 & 0,0125 & 0,0000 & 0,0001 & 48,5855 & 99,9 & $4,75 \mathrm{E}-15$ & 450,57 & 3,99 \\
\hline & $1600-02 J$ & 3,8 & 50,3931 & 0,0192 & 0,8069 & 0,0058 & 48,7703 & 96,7 & $4,80 \mathrm{E}-15$ & 452,09 & 3,89 \\
\hline & $1600-02 \mathrm{~K}$ & 6,0 & 52,1176 & 0,0135 & 0,1914 & 0,0025 & 51,4019 & 98,6 & $1,63 \mathrm{E}-14$ & 473,53 & 2,02 \\
\hline & $1600-03 \mathrm{~A}$ & 1,0 & 46,9228 & $-0,0151$ & 0,0000 & $-0,0114$ & 50,2940 & 107,2 & $7,77 \mathrm{E}-16$ & 464,54 & 17,55 \\
\hline & 1600-03B & 1,6 & 42,7236 & 0,0143 & 0,3182 & 0,0031 & 41,8411 & 97,9 & $6,45 \mathrm{E}-15$ & 394,36 & 2,97 \\
\hline & $1600-03 \mathrm{C}$ & 2,2 & 42,6265 & 0,0132 & 0,1121 & 0,0001 & 42,6050 & 99,9 & 8,70 E- 15 & 400,81 & 2,23 \\
\hline & $1600-03 \mathrm{D}$ & 2,7 & 42,4352 & 0,0107 & 0,0000 & $-0,0023$ & 43,1077 & 101,6 & $5,87 \mathrm{E}-15$ & 405,05 & 3,39 \\
\hline & $1600-03 E$ & 3,3 & 43,5973 & 0,0184 & 0,6098 & 0,0033 & 42,6896 & 97,9 & $3,81 \mathrm{E}-15$ & 401,52 & 5,06 \\
\hline & $1600-03 \mathrm{~F}$ & 4,8 & 43,7744 & 0,0148 & 0,3486 & 0,0007 & 43,5926 & 99,6 & $3,25 \mathrm{E}-15$ & 409,12 & 5,38 \\
\hline & $1600-03 \mathrm{G}$ & 5,2 & 49,0469 & 0,0149 & 0,1912 & 0,0028 & 48,2389 & 98,3 & $5,36 \mathrm{E}-15$ & 447,72 & 3,70 \\
\hline & $1600-03 \mathrm{H}$ & 4,0 & 52,5434 & 0,0111 & 0,3881 & $-0,0007$ & 52,7992 & 100,5 & $8,56 \mathrm{E}-15$ & 484,82 & 2,72 \\
\hline & 1600-03I & $6,0^{\circ}$ & 50,2424 & 0,0119 & 0,0000 & 0,0000 & 50,2521 & 100,0 & $3,12 \mathrm{E}-13$ & 464,19 & 0,90 \\
\hline & & & & & & & Idade méd & ia ponde & erada (2s): & 419 & 3 \\
\hline \multirow[t]{13}{*}{ CO-110 feldspa } & $1602-01 \mathrm{~A}$ & 0,4 & 62,7333 & $-0,4577$ & 5,0073 & 0,1956 & 5,2831 & 8,4 & $4,40 \mathrm{E}-17$ & 54,81 & 672,61 \\
\hline & 1602-01B & 0,7 & 66,4486 & 0,1445 & 10,2292 & 0,1213 & 31,6502 & 47,3 & $1,21 \mathrm{E}-16$ & 305,95 & 227,14 \\
\hline & $1602-01 \mathrm{C}$ & 1,1 & 51,0349 & 0,1293 & 12,7428 & 0,2050 & $-8,5915$ & - & - & - & - \\
\hline & 1602-01D & 1,5 & 62,5302 & $-0,0706$ & 0,0000 & $-0,0713$ & 83,5967 & 133,7 & $3,86 \mathrm{E}-16$ & 717,18 & 48,90 \\
\hline & $1602-01 \mathrm{E}$ & 2,0 & 46,9323 & 0,0203 & 0,0246 & 0,0128 & 43,1640 & 92,0 & $1,15 \mathrm{E}-15$ & 405,52 & 14,79 \\
\hline & $1602-01 \mathrm{~F}$ & 2,6 & 44,8675 & 0,0095 & 0,3998 & 0,0015 & 44,4612 & 99,1 & $3,22 \mathrm{E}-15$ & 416,40 & 6,43 \\
\hline & $1602-01 \mathrm{G}$ & 3,2 & 44,8126 & 0,0102 & 0,3019 & 0,0019 & 44,2776 & 98,8 & $3,62 \mathrm{E}-15$ & 414,87 & 5,60 \\
\hline & $1602-01 \mathrm{H}$ & 4,0 & 45,7690 & $-0,0015$ & 0,0000 & $-0,0127$ & 49,5231 & 108,2 & $3,33 \mathrm{E}-15$ & 458,25 & 6,79 \\
\hline & 1602-01I & 4,8 & 45,1257 & 0,0033 & 0,0000 & $-0,0102$ & 48,1329 & 106,7 & 3,36E-15 & 446,85 & 10,64 \\
\hline & $1602-01 \mathrm{~J}$ & 5,2 & 46,1418 & 0,0103 & 0,0000 & $-0,0009$ & 46,3952 & 100,6 & $3,64 \mathrm{E}-14$ & 432,50 & 1,11 \\
\hline & $1602-02 \mathrm{~A}$ & 2,5 & 98,7876 & 0,0441 & 0,0000 & 0,1670 & 49,4265 & 50,0 & $2,46 \mathrm{E}-15$ & 457,46 & 25,77 \\
\hline & $1602-02 B$ & 3,8 & 46,6482 & 0,0179 & 0,0995 & 0,0051 & 45,1400 & 96,8 & $1,22 \mathrm{E}-15$ & 422,07 & 12,46 \\
\hline & $1602-02 \mathrm{C}$ & 4,8 & 49,1274 & $-0,0116$ & 0,0000 & $-0,0194$ & 54,8511 & 111,7 & $6,98 \mathrm{E}-16$ & 501,27 & 21,06 \\
\hline \multirow[t]{11}{*}{ CO-110 feldspato } & $1602-02 \mathrm{D}$ & 5,1 & 46,2698 & 0,0594 & 3,6740 & 0,0488 & 32,2259 & 69,5 & $3,68 \mathrm{E}-16$ & 311,06 & 40,40 \\
\hline & $1602-02 \mathrm{E}$ & 5,2 & 46,6360 & 0,0092 & 0,0000 & $-0,0041$ & 47,8374 & 102,6 & $1,49 \mathrm{E}-15$ & 444,42 & 8,88 \\
\hline & $1602-03 \mathrm{~A}$ & 2,0 & 56,0838 & 0,0162 & 0,3930 & 0,0112 & 52,8193 & 94,2 & $9,78 \mathrm{E}-15$ & 484,98 & 3,02 \\
\hline & 1602-03B & 3,2 & 46,7454 & 0,0109 & 0,0000 & $-0,0009$ & 47,0124 & 100,6 & $2,05 \mathrm{E}-14$ & 437,61 & 1,39 \\
\hline & $1602-03 \mathrm{C}$ & 4,8 & 46,3021 & 0,0120 & 0,1481 & $-0,0001$ & 46,3508 & 100,1 & $2,68 \mathrm{E}-14$ & 432,14 & 1,38 \\
\hline & 1602-03D & 2,5 & 47,2670 & 0,0120 & 0,0000 & 0,0000 & 47,2684 & 100,0 & $1,85 \mathrm{E}-13$ & 439,73 & 0,90 \\
\hline & $1602-03 \mathrm{~F}$ & 3,0 & 47,5175 & 0,0120 & 0,0000 & 0,0001 & 47,4825 & 99,9 & $3,00 \mathrm{E}-13$ & 441,50 & 0,71 \\
\hline & $1602-03 \mathrm{G}$ & 4,2 & 47,5793 & 0,0121 & 0,0061 & 0,0001 & 47,5643 & 100,0 & $2,77 \mathrm{E}-13$ & 442,17 & 0,81 \\
\hline & $1602-03 \mathrm{H}$ & 5,0 & 47,3790 & 0,0118 & 0,0474 & $-0,0007$ & 47,5767 & 100,4 & $3,32 \mathrm{E}-14$ & 442,27 & 1,17 \\
\hline & $1602-03 \mathrm{I}$ & 6,0 & 47,4856 & 0,0119 & 0,0015 & 0,0001 & 47,4687 & 100,0 & $7,66 \mathrm{E}-13$ & 441,38 & 0,82 \\
\hline & & & & & & & \multicolumn{3}{|c|}{ Idade média ponderada ( $2 \mathrm{~s})$ : } & 440 & 2 \\
\hline
\end{tabular}


Tabela 3 - (Continuação).

\begin{tabular}{|c|c|c|c|c|c|c|c|c|c|c|c|c|}
\hline Amostra & Material & N" Lab & $\begin{array}{c}\text { Laser } \\
\text { (W) }\end{array}$ & $40 / 39$ & $38 / 39$ & $37 / 39$ & $36 / 39$ & $40 * / 39$ & $\% \operatorname{Rad}$ & $\begin{array}{c}\text { Ar40 } \\
\text { (mols) }\end{array}$ & $\begin{array}{c}\text { Idade } \\
\text { (Ma) }\end{array}$ & $\begin{array}{l} \pm(1 \mathrm{~s}) \\
\text { (Ma) }\end{array}$ \\
\hline \multirow[t]{24}{*}{ CO-57 } & biotita & $1601-01 \mathrm{~A}$ & 0,3 & 40,7417 & 0,0257 & 0,0253 & 0,0146 & 36,4378 & 89,4 & $7,95 \mathrm{E}-16$ & 348,02 & 18,76 \\
\hline & & 1601-01B & 0,6 & 51,5685 & 0,0144 & 0,0000 & 0,0070 & 49,5055 & 96,0 & $1,00 \mathrm{E}-14$ & 458,10 & 2,97 \\
\hline & & $1601-01 \mathrm{C}$ & 0,9 & 50,7004 & 0,0137 & 0,0464 & 0,0018 & 50,1811 & 99,0 & $3,36 \mathrm{E}-14$ & 463,62 & 1,23 \\
\hline & & 1601-01D & 1,2 & 50,6895 & 0,0119 & 0,0000 & $-0,0012$ & 51,0468 & 100,7 & $1,55 \mathrm{E}-14$ & 470,66 & 2,18 \\
\hline & & $1601-01 \mathrm{E}$ & 1,6 & 50,5174 & 0,0118 & 0,0000 & $-0,0019$ & 51,0665 & 101,1 & $1,37 \mathrm{E}-14$ & 470,81 & 1,58 \\
\hline & & $1601-01 \mathrm{~F}$ & 2,0 & 50,7454 & 0,0118 & 0,0000 & $-0,0001$ & 50,7757 & 100,1 & $1,17 \mathrm{E}-14$ & 468,45 & 2,47 \\
\hline & & $1601-01 \mathrm{G}$ & 2,6 & 50,4502 & 0,0126 & 0,0495 & 0,0001 & 50,4288 & 100,0 & $1,90 \mathrm{E}-14$ & 465,63 & 1,75 \\
\hline & & $1601-01 \mathrm{H}$ & 3,8 & 50,8798 & 0,0131 & 0,0305 & 0,0005 & 50,7282 & 99,7 & $3,57 \mathrm{E}-14$ & 468,07 & 1,25 \\
\hline & & 1601-01I & 5,2 & 51,4089 & 0,0103 & 0,0366 & $-0,0039$ & 52,5507 & 102,2 & $1,11 \mathrm{E}-14$ & 482,82 & 2,41 \\
\hline & & $1601-02 \mathrm{~A}$ & 0,6 & 51,9763 & 0,0143 & 0,0788 & 0,0067 & 50,0109 & 96,2 & $3,18 \mathrm{E}-14$ & 462,23 & 1,52 \\
\hline & & $1601-02 B$ & 0,9 & 50,7797 & 0,0126 & 0,0677 & 0,0012 & 50,4396 & 99,3 & $5,26 \mathrm{E}-14$ & 465,72 & 1,19 \\
\hline & & $1601-02 \mathrm{C}$ & 1,3 & 50,8216 & 0,0124 & 0,1178 & 0,0008 & 50,6097 & 99,6 & $3,80 \mathrm{E}-14$ & 467,10 & 1,27 \\
\hline & & 1601-02D & 1,8 & 51,1551 & 0,0119 & 0,0318 & 0,0005 & 51,0153 & 99,7 & $2,82 \mathrm{E}-14$ & 470,40 & 1,29 \\
\hline & & 1601-02E & 2,8 & 50,9299 & 0,0120 & 0,0000 & 0,0005 & 50,7826 & 99,7 & $4,48 \mathrm{E}-14$ & 468,51 & 1,33 \\
\hline & & $1601-02 \mathrm{~F}$ & 3,6 & 51,2802 & 0,0132 & 0,0086 & 0,0009 & 51,0016 & 99,5 & $6,21 \mathrm{E}-14$ & 470,29 & 1,23 \\
\hline & & $1601-02 \mathrm{G}$ & 5,2 & 50,9827 & 0,0123 & 0,0225 & 0,0006 & 50,8188 & 99,7 & $6,20 \mathrm{E}-14$ & 468,80 & 0,98 \\
\hline & & $1601-03 \mathrm{~A}$ & 0,6 & 52,3337 & 0,0132 & 0,0068 & 0,0037 & 51,2416 & 97,9 & $2,66 \mathrm{E}-14$ & 472,24 & 1,65 \\
\hline & & 1601-03B & 0,9 & 51,8249 & 0,0129 & 0,0093 & 0,0002 & 51,7555 & 99,9 & $5,47 \mathrm{E}-14$ & 476,40 & 1,08 \\
\hline & & $1601-03 C$ & 1,4 & 51,6693 & 0,0121 & 0,0000 & $-0,0002$ & 51,7414 & 100,1 & $4,57 \mathrm{E}-14$ & 476,28 & 1,21 \\
\hline & & $1601-03 \mathrm{D}$ & 2,0 & 51,8880 & 0,0123 & 0,0000 & $-0,0005$ & 52,0257 & 100,3 & $3,11 \mathrm{E}-14$ & 478,58 & 1,41 \\
\hline & & $1601-03 E$ & 2,7 & 52,0062 & 0,0121 & 0,0000 & $-0,0004$ & 52,1207 & 100,2 & $3,67 \mathrm{E}-14$ & 479,35 & 1,53 \\
\hline & & $1601-03 \mathrm{~F}$ & 3,6 & 51,8138 & 0,0129 & 0,0289 & 0,0006 & 51,6252 & 99,6 & $5,38 \mathrm{E}-14$ & 475,34 & 1,20 \\
\hline & & $1601-03 \mathrm{G}$ & 5,2 & 51,7423 & 0,0121 & 0,0307 & 0,0000 & 51,7460 & 100,0 & $6,20 \mathrm{E}-14$ & 476,32 & 1,08 \\
\hline & & & & & & & & Idade mé & lia pond & erada (2s): & 472 & 2 \\
\hline
\end{tabular}

